CENTRE for ECONOMIC

$\begin{array}{lllllllllll}P & E & \mathrm{~F} & \mathrm{O} & \mathrm{R} & \mathrm{M} & \mathrm{A} & \mathrm{N} & \mathrm{C} & \mathrm{E}\end{array}$

CEP Discussion Paper No 1695

May 2020

\title{
Automation, Globalization and Vanishing Jobs: \\ A Labor Market Sorting View
}

\author{
Ester Faia \\ Sébastien Laffitte \\ Maximilian Mayer \\ Gianmarco Ottaviano
}




\begin{abstract}
We show, theoretically and empirically, that the effects of technological change associated with automation and offshoring on the labor market can substantially deviate from standard neoclassical conclusions when search frictions hinder efficient assortative matching between firms with heterogeneous tasks and workers with heterogeneous skills. Our key hypothesis is that better matches enjoy a comparative advantage in exploiting automation and a comparative disadvantage in exploiting offshoring. It implies that automation (offshoring) may reduce (raise) employment by lengthening (shortening) unemployment duration due to higher (lower) match selectivity. We find empirical support for this implication in a dataset covering 92 occupations and 16 sectors in 13 European countries from 1995 to 2010.
\end{abstract}

Key words: automation, offshoring, two-sided heterogeneity, positive assortativity, wage inequality, horizontal specialization, core-task-biased technological change

JEL Codes: O33, O47, F16, F66, J64

This paper was produced as part of the Centre's Trade Programme. The Centre for Economic Performance is financed by the Economic and Social Research Council.

We thank Daron Acemoglu, Pol Antras, Björn Brügemann, Francesco Caselli, Gabriel ChorodowReich, David Dorn, Jan Eeckhout, Paul Gautier, Fatih Guvenen, Gordon Hanson, Erik Hurst, Nir Jaimovich, Juan F. Jimeno, Marianna Kudlyak, Sang Yoon Lee, Yaniv Yedid-Levi, Alan Manning, Nicolas Pedrosky-Nadeau, Florian Scheuer and Chris Tonetti and participants at various conferences and seminars for useful comments.

Ester Faia, Goethe University Frankfurt and CEPR. Sébastien Laffitte, ENS Paris-Saclay and CREST. Maximilian Mayer, Goethe University Frankfurt. Gianmarco Ottaviano, Bocconi University, Baffi-CAREFIN, IGIER, CEPR and Centre for Economic Performance, London School of Economics.

Published by

Centre for Economic Performance

London School of Economics and Political Science

Houghton Street

London WC2A $2 \mathrm{AE}$

All rights reserved. No part of this publication may be reproduced, stored in a retrieval system or transmitted in any form or by any means without the prior permission in writing of the publisher nor be issued to the public or circulated in any form other than that in which it is published.

Requests for permission to reproduce any article or part of the Working Paper should be sent to the editor at the above address.

(c) E. Faia, S. Laffitte, M. Mayer and G. Ottaviano, submitted 2020. 


\section{Introduction}

Automation and offshoring are two of the most debated contemporary long-run trends. They are perceived as having a disruptive effect on the labour market with worrying implications for inequality in terms of both employment opportunities and wages across different groups of workers. Understanding their effects, their relative importance and their possible interactions is, therefore, of preeminent relevance and, as such, has attracted a lot of research. ${ }^{1}$

Conventional wisdom, based on neoclassical reasoning about technological progress, is that both trends are not going to have different effects from those of previous industrial revolutions as in the end both can be seen as two types of 'technological change'. With constant-return-to-scale technologies, competitive input markets and homothetic preferences, the neoclassical paradigm predicts that any improvement in the state of technology leads to an increase in labor productivity. In turn, higher labor productivity maps into higher wages, which raise demand so as to compensate the investment that fosters technological change in the first place. Labor demand, hence employment, cannot deviate from the longrun path dictated by the evolution of labor productivity. This argument is very general and stands also in the presence of skill-biased technological change (SBTC), whereby new technology complements workers with high skills, or routine-biased technological change (RBTC), whereby technology crowds out workers from repetitive tasks (see e.g. Acemoglu and Restrepo, 2018b, for a detailed discussion). It highlights a win-win situation as the efficiency gains in production eventually trickle down to both capital owners and workers. If labor is the only factor of production and the relative price of investment goods declines, then workers as a whole gain from new technology. Moreover, if the supply of labor to different occupations is perfectly elastic, then all workers gain (Caselli and Manning, 2019).

People do observe, however, a number of facts (such as decreasing labor share, vanishing jobs especially in manufacturing, and increasing inequality) that might challenge the rosy neoclassical view. Concerns have been raised about the impact of automation on labor demand from various angles. ${ }^{2}$ Similar concerns have also been raised with respect to offshoring as this is seen to work just like a new production technology. ${ }^{3}$ More generally, some commen-

\footnotetext{
${ }^{1}$ See e.g. Autor and Dorn (2009), Ottaviano, Peri and Wright (2013), Goos, Manning and Salomons (2014), Graetz and Michaels (2015), Acemoglu and Restrepo (2020), Dauth et al. (2017) on the empirical side; Acemoglu and Autor (2011),Aghion, Jones and Jones (2017), Acemoglu and Restrepo (2018b) and Acemoglu and Restrepo (2018a), Caselli and Manning (2019) on the theoretical one. Most of these studies tend to focus more on the effects of either automation or globalization than on their interactions. Empirical assessments of their simultaneous effects across US regions can be found e.g. in Autor, Dorn and Hanson (2013, 2015) and with a global perspective, both theoretically and empirically, in e.g. Arkolakis et al. (2018).

${ }^{2}$ See for instance Bostrom (2014), Brynjolfsson and McAfee (2014), Goos, Manning and Salomons (2014), Ford (2015), Susskind and Susskind (2015), White House (2016), Stone (2016), Frey and Osbourne (2013), Caselli and Manning (2019).

${ }^{3}$ Grossman and Rossi-Hansberg (2008), Costinot and Vogel (2010), Goos, Manning and Salomons (2014), Ottaviano, Peri and Wright (2013)
} 
tators fear that things are very different this time when compared with previous industrial revolutions. ${ }^{4}$ All these concerns can be rationalized only if one departs from the neoclassical paradigm in that, from a theoretical viewpoint, any threat to wages and employment may be expected to come more from the impacts of new technology on the competitiveness of markets in the presence of various types of frictions than from changes in the production function in the presence of frictionless markets (Caselli and Manning, 2019).

Against this backdrop, the aim of the present paper is to show, theoretically and empirically, that the effects of technological change associated with automation and offshoring on the labor market can substantially deviate from the rosy neoclassical conclusions when search frictions hinder the efficient assortative matching between firms that need heterogeneous tasks to be performed and workers who are endowed with heterogeneous skills to perform those tasks. The type of heterogeneity we have in mind is 'horizontal' rather than 'vertical' as usually assumed in the literature on skill-biased or routine-biased technological change. In models of skill-biased technological change some tasks are more 'skill intensive' than others and some skills are 'higher' in a vertical scale than others. In the dominant case of positive assortative matching, high-skill workers end up performing more skill-intensive tasks. Skill-biased technological change then increases the relative demand of high-skill workers to the detriment of low-skill ones, boosting the skill premium. The same logic works in models of routine-biased technological change, the only difference being that the skill intensity of tasks is replaced by their 'routine intensity' and the high-low ranking of skills is replaced by a ranking in terms of routineness. Analogously, routine-biased technological change increases the relative demand of non-routine workers to the detriment of routine ones, boosting the non-routine premium.

While SBTC and RBTC are very relevant concepts, here we want to highlight additional effects of automation and offshoring that are at work independently from any vertical heterogeneity. From a theoretical point of view, our hypothesis is the following. With two-sided heterogeneity, firms and workers have 'ideal matches', that is, matches that produce the highest surplus. However, in the presence of search frictions, meetings do not necessarily lead to ideal matches. Hence, whenever a firm and a worker meet with a less-than-ideal counterpart, they both face a trade-off between accepting the current match and leaving in search of a better match. A better match generates higher surplus but this gain has to be discounted as time is lost in search. That is why in equilibrium firms (workers) settle for an 'acceptance set' of workers (firms) with skills (tasks) that are 'good enough' for them, in the sense that they generate enough surplus. The intersection between the two acceptance sets determines the 'matching set' of productive matches that are implemented. The larger the acceptance sets and thus the matching set, the higher the inefficiency in production due to

\footnotetext{
${ }^{4}$ Bowen (1966), Akst (2013), Brynjolfsson and McAfee (2014), Autor (2015).
} 
more 'mismatch' between tasks and skills. Meetings that are not converted into productive matches generate frictional unemployment. ${ }^{5}$

Our hypothesis is then that automation may increase the productivity of ideal matches relative to less-than-ideal ones, above and beyond any consideration of skill or routine bias. It may, therefore, make firms and workers more 'selective', reducing their acceptance sets as they become more willing to forgo the surplus of a less-than-ideal match while waiting for a better one. Increased selectivity is good for the productive efficiency of matches that are eventually formed as 'mismatch' in the matching set diminishes. However, as firms and workers are willing to sit longer on the fence waiting for better matches, unemployment rises. Moreover, for matches that are actually formed, ideal matches end up commanding a higher premium with respect to less-than-ideal matches. The result is that automation leads to higher match productivity, but also lower employment and more wage inequality. Increased match selectivity interferes with the standard neoclassical forces and materializes as long as less-than-ideal skills and tasks become less substitutable with ideal ones. As ideal matches are the ones that define firms' and workers' core competencies, we use 'core-biased technological change' (CBTC) to label the way technology evolves in our conceptual framework. Differently, offshoring may increase the productivity of less-than-ideal matches relative to ideal ones by allowing firms to unbundle tasks into subtasks to be allocated to home and foreign workers depending on their comparative advantages. It may, therefore, make firms and home workers less selective, enlarging their acceptance sets as they become less willing to forgo the surplus of a less-than-ideal match while waiting for a better one. On the one hand, decreased selectivity is bad for the productive efficiency of matches that are eventually formed as 'mismatch' in the matching set increases. On the other hand, match surplus may still increase thanks to specialization according to comparative advantage. As firms and workers are less willing to sit on the fence waiting for better matches, unemployment falls. Moreover, ideal matches end up commanding a lower premium with respect to less-thanideal matches. Hence, differently from automation, offshoring may lead not only to higher match productivity, but also to higher employment and less wage inequality.

We formalize our hypothesis through a growth model that, beyond neoclassical forces, features search frictions in the labor market and assortativity with two-sided heterogeneity of horizontally differentiated skills and tasks. Workers and firms are risk-neutral and maximize lifetime discounted utility in continuous time. The random part of the matching process, based on a one-to-one relation, is governed by a canonical constant return to scale function (see Mortensen and Pissarides, 1994). Workers' skills and firms' tasks are uniformly and symmetrically distributed around a circle that describes the space of their heterogeneous

\footnotetext{
${ }^{5}$ For an analogous modeling of the labor market with vertically differentiated skills and tasks see Shimer and Smith (2000) and, more recently, Hagedorn, Law and Manovskii (2017).
} 
characteristics. Due to search frictions, workers and firms do not match efficiently, but instead search and accept matches in an interval around their ideal ones. The distance between matched skill and task affects match surplus. This is log-submodular (log-supermodular) in automation (offshoring) and matches at shorter (longer) distance have a comparative advantage in exploiting automation (offshoring). How automation and offshoring affect labor market outcomes depends on the interactions among four effects. Automation increases the productivity of any given match ('productivity effect'), but also increases the relative productivity of ideal matches relative to less-than-ideal ones ('mismatch effect'). In parallel, offshoring increases the productivity of any given match thanks to domestic workers' subtask specialization ('specialization effect'), but also decreases the subset of subtasks assigned to them ('substitution effect'). Accordingly, while the productivity and specialization effects of automation and offshoring increase the match surplus of domestic firms and workers, their mismatch and substitution effects work in the opposite direction. Due to these opposite effects, employment is an inverted U-shaped function of both automation and offshoring: productivity and specialization effects dominate when automation and offshoring are limited whereas mismatch and substitution effects dominate when automation and offshoring have already reached an advanced stage.

Survey evidence suggests that selectivity due CBTC could be quite important. Having difficulty 'finding the right skills or talent' or 'filling jobs' is often quoted by policy-makers as one of the main issues raised by employers. For example, the 2018 Talent Shortage Survey by Manpower Group (2018) highlights how talent shortage is increasing over time leaving a growing number of jobs unfilled all around the world. ${ }^{6}$ In most cases in which applicants are not talented enough for the job, only $40 \%$ of the firms report that it is a skill issue, while $60 \%$ of them stress a lack of experience or human strengths. The implied talent shortage is strongly linked to technology, but does not necessarily depend on a dearth of workers with higher education: "Most of the top ten in-demand roles today require post-secondary training and not always a full university degree.[... In the digital age, employment will not always require a college degree, but will rely heavily on continual skills development as even the most traditional roles are augmented with new technology" (Manpower Group, 2018, p.6). A wide range of jobs with different education and routine contents are affected across sectors. Higher than average recruitment bottlenecks tend to be reported in manufacturing, ICT and health care for jobs such as skilled trades workers, machine operators, sales representatives, engineers, technicians, ICT professionals, workers in marketing posts, drivers and

\footnotetext{
${ }^{6}$ The 2018 Talent Shortage Survey by ManpowerGroup covers 39,195 employers across six industry sectors in 43 countries and territories: Argentina, Australia, Austria, Belgium, Brazil, Bulgaria, Canada, China, Colombia, Costa Rica, Czech Republic, Finland, France, Germany, Greece, Guatemala, Hong Kong, Hungary, India, Ireland, Israel, Italy, Japan, Mexico, Netherlands, New Zealand, Norway, Panama, Peru, Poland, Portugal, Romania, Singapore, Slovakia, Slovenia, South Africa, Spain, Sweden, Switzerland, Taiwan, Turkey, UK and USA.
} 
office support staff (Cedefop Eurofound, 2018). ${ }^{7}$ Take, for instance, the case of machine operators. These are required to have machine-specific experience ranging from the knowledge of production procedures to the ability to understand blueprints, schematics and manuals. Due to technological change, they are also increasingly required to be familiar with Computer Numerical Control (CNC), through which, starting with digitized data, a computer and a Computer Aided Manufacturing (CAM) program is used to control, automate, and monitor the movements of a given machine. The machine can be a milling machine, lathe, router, welder, grinder, laser or waterjet cutter, sheet metal stamping machine, robot, or many other types of machines, each with its own specific blueprints, schematics and manuals. ${ }^{8}$ A concern for both firms and workers is that retraining from a known to a new machine can be a costly time-consuming process, making them cautious about potential mismatch. ${ }^{9}$

However, whether our theoretical mechanism indeed operates in practice, and the mismatch effect is strong enough to reverse the neoclassical conclusions, is in the end an empirical issue that goes beyond simple survey evidence. We tackle this issue by capturing firms' and workers' match selectivity at the sector-occupation level. In the wake of Costinot and Vogel (2010) the underlying idea is that, while a sector may cover a rich menu of occupations, these include a submenu of 'core' occupations that are disproportionately concentrated in the sector. In this respect, an increase in the concentration of occupations' employment across sectors can be interpreted as an increase in match selectivity.

We focus on 92 occupations at the 3-digit ISCO-88 level and 16 (out of 21) sectors according to the NACE Rev.2 classification. ${ }^{10}$ Our dataset covers 13 European countries for the period 1995 - 2010. This allows us to test the mechanisms of our model in many different countries with heterogeneous characteristics. The dataset includes information on employment from the European Labour Force Survey (EU-LFS). It also includes occupational indices of 'automatability' following Acemoglu and Autor (2011) and 'offshorability' following Blinder and Krueger (2013). We use these indices to infer actual automation and offshoring in the subsequent years, which we do not observe. The underlying idea here is that automation and offshoring are two general long-run trends whose effects can be assessed in terms of the

\footnotetext{
${ }^{7}$ In spring 2014 the European Centre for the Development of Vocational Training of the European Union (Cedefop) undertook the first European skills and jobs survey (ESJS), a large-scale primary data collection of about 49,000 adult employees in 28 EU Member States. Cedefop Eurofound (2018) summarizes many of the insights gained by closer empirical scrutiny of this new European data set.

${ }^{8}$ See https://wiki.mcneel.com/rhino/cncbasics.

${ }^{9}$ This is consistent with evidence collected by Bartel, Ichniowski and Shaw (2007) and Koren, Csillag and Köllo (2020), according to which workers assigned to new machines or IT-enhanced capital equipment are required to have 'better' technical and problem-solving skills. These are likely to be horizontally differentiated and acquired mostly through experience as highlighted by Dauth et al. (2019). Koren, Csillag and Köllo (2020) also find that the productivity of workers assigned to new machines rises and their wages increase but become more unequal.

${ }^{10}$ We exclude occupations and sectors closely associated with public and agricultural activities.
} 
differential exposure of different occupations to them. To investigate the empirical relevance of our specific mechanism linking automation and offshoring to labor market outcomes, we construct an index of selectivity that can be computed with our data based on the notion of employers' and employees' matching set. The index proxies the size of this set through the 'sectoral selectivity of occupations' (SSO) defined as the concentration of occupations' employment across sectors. This index is meant to inversely capture the willingness of firms and workers to accept less-than-ideal matches: selectivity is considered to be higher (lower) for larger (smaller) values of SSO.

In line with our model we find that over the period of observation sectors with higher initial automatability experience a differential increase in selectivity. This effect is driven by occupations with above-median automatability while there is no impact on selectivity for occupations characterized by below-median automatability. We also find that, again in line with our model's mechanism, sectors with higher initial offshorability experience a differential decrease in selectivity. Using recent methods proposed by Berg and Streitz (2019), we conclude that these differentials are not driven by spillover effects. Our results continue to hold when we use more standard selectivity measures borrowed from the literature, such as 'skill mismatch' and 'unemployment duration'. Next, we document a robust negative impact of selectivity on employment at the occupation level. To control for potential endogeneity, we employ an instrumental variable strategy close to the double-Bartik strategy implemented by Chodorow-Reich and Wieland (forthcoming). The negative effect of selectivity on employment materializes especially in occupations with above-median automatability. Finally, by putting together the results on the impacts of automatability and offshorability on selectivity with those on the impact of selectivity on employment, we can conclude that automation reduces (offshoring increases) employment through the selectivity channel described in the our theoretical model.

The rest of the paper is structured as follows. Section 2 introduces and solves the model. Section 3 presents the dataset, some descriptive statics and the regression results. Section 4 concludes.

\section{A Model of 'Core-Biased Technological Change'}

We want to investigate how automation and offshoring affect employment and wage inequality when they change the matching and sorting patterns between firms' heterogeneous tasks and workers' heterogeneous skills in the presence of search frictions. ${ }^{11}$ To this aim, we model

\footnotetext{
${ }^{11}$ Two-sided heterogeneity is featured in models of assortative matching à la Becker (1974) and their applications to the labour market. Influential applications, including Shimer and Smith (2000) and Hagedorn, Law and Manovskii (2017), insert two-sided vertical heterogeneity and general assortativity into models with search and matching frictions. Differently from them, given the specific nature of our research question, we
} 
the steady state of a sector in a small open economy that freely trades goods and capital with the rest of the world. The sector supplies a freely traded homogeneous final product under perfect competition. The price of the final product is determined in the international market and set to 1 without loss of generality. Domestic firms supply the final product by employing a domestic worker each, and a variable amount of capital. This is homogeneous and hired at given rental rate $\rho$ in a perfectly competitive international capital market.

Domestic workers perform firm-specific horizontally differentiated tasks and are themselves horizontally differentiated in terms of task-specific skills. Two-sided heterogeneity of domestic firms' tasks and workers' skills is associated with search frictions that give rise to possible skill-task 'mismatch'. ${ }^{12}$ We model such heterogeneity by placing firms' tasks and workers' skills in a characteristics space. In particular, we place firms and workers at different 'addresses' continuously distributed along a unit circle (i.e. with radius $1 / 2 \pi$ ). Performing each task requires a domestic worker with the appropriate skill. There is an ideal match of each task with the most appropriate skill, which is the one with the same address as the task along the circle. The ideal match delivers the maximum achievable productivity. Lessthan-ideal matches are also productive, but their productivity decreases with the distance $d \in[0,1 / 2]$ between their matched task's and skill's addresses along the circle. Minimum productivity thus corresponds to matches at distance $1 / 2$. Matches between tasks and skills are not necessarily ideal as search frictions make firms and workers willing to accept lessthan-ideal matches. This is how search frictions will induce 'mismatch' (measured by the value of $d$ ) between tasks and skills, that is, divergence between the actual matches and the ideal ones. To introduce offshoring we assume that each task consists of a continuum of subtasks. These differ in terms of domestic workers' ability to perform them relative to foreign workers and only a subset of them will be assigned to domestic workers in equilibrium. When this subset shrinks, domestic workers specialize in subtasks which they are better at.

Within this framework, automation is modeled as an increase in the productivity of any given match ('productivity effect'), but also as an increase in the relative productivity of ideal matches relative to less-than-ideal ones ('mismatch effect'). In parallel, offshoring is modeled as an increase in the productivity of any given match thanks to domestic workers' subtask specialization ('specialization effect'), but also as a decrease in the subset of subtasks assigned to them ('substitution effect'). Accordingly, while the productivity and specialization effects of automation and offshoring increase the match surplus of domestic firms and workers, their mismatch and substitution effects work in the opposite direction.

\footnotetext{
focus on production functions with positive assortative matching and two-sided horizontal heterogeneity.

${ }^{12}$ Matches are one-worker-one-job relationships and therefore we do not consider the complementarities between workers within the same firm as in Eeckhout and Kircher (2018). While complementarities within the firms are certainly important, they are not immediately relevant for our purposes.
} 
Time is continuous and in each moment the timing of events is as follows. First, each domestic firm decides how much capital to rent and randomly meets some domestic worker. Next, upon observing their respective types (in terms of tasks or skills), the firm and the worker decide whether to match or not. Finally, if they decide to match, they bargain on the wage as a fraction of the match surplus according to the Nash protocol. The steady state pure strategy of each type of domestic firm (worker) is to decide which types of domestic workers (firms) to match with, taking the strategies of all other firms and domestic workers as given.

\subsection{Skills and Tasks}

All agents are risk-neutral, infinitely lived and maximize the present value of their future income streams, discounted by the common discount factor $\rho$. Along the unit circle, there is an exogenous measure of domestic workers with skills indexed $x \in[0,1]$ clockwise from noon ('skill address'). The distribution of skills across addresses is determined by a uniform p.d.f. $g_{w}(x)$. There is an exogenous measure $L$ of domestic workers. Given unit support, there are thus $L$ workers at each address. Likewise, there is an endogenous measure of firms with tasks indexed $y \in[0,1]$ clockwise from noon ('task address'). The distribution of tasks is also governed by a uniform p.d.f. $g_{f}(y)$ while the measure of domestic firms is determined by free entry. Uniformity is assumed for simplicity as it will lead to the same equilibrium outcome for all addresses. ${ }^{13}$

There is no asymmetric information in the model. All agents know their own type and the types of all potential partners they meet. Nonetheless, as already discussed, search frictions hamper the formation of ideal matches. ${ }^{14}$ This implies, first, that some meetings do not result in an employment relation, hence unemployment arises. Second, domestic firms (workers) do not consider only domestic workers (firms) with ideal skills (tasks), but they are also willing to hire workers (be hired by firms) with skills (tasks) in a range centered around their ideal skills (tasks). This is what induces mismatch between skills and tasks, measured by their distance along the circle:

$$
d(x, y)=\min [x-y+1, y-x]
$$

where the min function selects the shorter arc distance between clockwise and counterclockwise travels between $x$ and $y$ along the unit circle.

\footnotetext{
${ }^{13}$ In Appendix D we explicitly allow for asymmetry by additionally introducing vertical specialization.

${ }^{14}$ In the absence of search or information frictions all workers and firms would be matched to their optimal partner as in Becker (1974).
} 


\subsection{Production, Automation and Offshoring}

For the production function of a match we keep neoclassical assumptions so as to preserve the role of technological progress that increases total factor productivity, and thus workers' and firms' income. Specifically, we assume that a firm's technology frontier exhibits constant returns to scale with respect to both capital and labor. Capital is chosen endogenously, which serves the purpose of covering all neoclassical adjustment margins. By reducing the price of investment, an increase in productivity raises labor demand. In this respect, introducing capital is a conservative choice. If the cost of mismatch reduces employment, it will do so even in presence of a declining price of investment.

The functional form of a domestic firm's production technology is Cobb-Douglas:

$$
f(d)=A K(d)^{\beta} L(d)^{1-\beta}
$$

with $\beta \in(0,1)$, where $K(d)$ is capital, $L(d)$ refers to the efficiency units provided by the domestic worker whom the firm matches with, $d$ is 'mismatch' as measured by match distance (1), and $A>0$ is total factor productivity, which we will simply call 'automation' henceforth. ${ }^{15}$ The fact that larger $A$ raises output for given inputs captures the 'productivity effect' of automation. The surplus generated by the match is given by what is left of the value of production $f(d)$ after paying capital. As capital is hired in a perfectly competitive market, profit maximization implies that its rental rate and the value of its marginal productivity are equalized:

$$
\rho=\beta A K(d)^{\beta-1} L(d)^{1-\beta} .
$$

Solving (3) for $K(d)$ and substituting the result into (2) net of capital remuneration gives match surplus:

$$
s(d)=f(d)-\rho K(d)=\Phi A^{\frac{1}{1-\beta}} L(d)
$$

with bundling parameter $\Phi \equiv(1-\beta)(\beta / \rho)^{\frac{\beta}{1-\beta}}$. The efficiency units provided by the domestic worker depend on which subtasks the worker performs. Specifically, each task $d$ consists of a continuum of subtasks indexed $i \in[0,1]$ in increasing order of ability by the domestic worker to perform them. When assigned subtask $i$ of task $d$, the number of efficiency units of labor the worker is able to provide is given by:

$$
L(d, i)=F i-\frac{\gamma A}{2} d .
$$

\footnotetext{
${ }^{15} A$ subsumes all sources of productivity gains. Let $b_{K}, b_{L}$ and $B$ capture capital-enhancing, laborenhancing and Hicks-neutral technological change. With Cobb-Douglas technology we have $f(d)=$ $B\left(b_{K} K(d)\right)^{\beta}\left(b_{L} L(d)\right)^{1-\beta}$, which can be rewritten as (2) after defining $A \equiv B\left(b_{K}\right)^{\beta}\left(b_{L}\right)^{1-\beta}$.
} 
Effective labor rises as $i$ increases. Moreover, effective labor equals $F i \geq 0$ for the ideal match $(d=0)$ and declines as $d$ increases until it reaches its minimum $F i-\gamma A / 4$ for the worst match $(d=1 / 2)$. The decline is steeper for better states of technology (larger $A$ ), which captures the idea that automation increases the loss from less-than-ideal matching ('mismatch effect').

Offshoring is introduced as follows. Let $\Omega \in[0,1]$ denote the subtask the firm assigns to the domestic worker which the worker is worst at, such that subtasks $i \in(\Omega, 1]$ are assigned to this worker whereas subtasks $i \in[0, \Omega)$ are offshored. Accordingly, $\Omega$ is the measure of offshored subtasks and we will refer to it as simply 'offshoring' henceforth. Given (5), the efficiency units the domestic worker provides to the matched domestic firm then evaluate to:

$$
L(d)=\int_{\Omega}^{1} L(d, i) d i=\frac{1}{2}(1-\Omega)[F(1+\Omega)-\gamma A d]
$$

This expression reveals the existence of two opposing effects of offshoring on effective labor. Larger $\Omega$ reduces the measure of subtasks assigned to the domestic worker through $(1-\Omega)$ ('substitution effect'), but it also increases the worker's average ability in the performed tasks through $(1+\Omega)$ ('specialization effect'). By (4) and (6), match surplus for mismatch $d$ can be finally expressed as:

$$
s(d)=\frac{\Phi}{2} A^{\frac{1}{1-\beta}}(1-\Omega)[F(1+\Omega)-\gamma A d]
$$

for $d \in[0, F(1+\Omega) / \gamma A]$ and zero otherwise.

A few summary remarks are in order with reference to (7). First, for given $A$ and $\Omega$, match surplus $s(d)$ is a decreasing linear function of mismatch $d$ with slope increasing in $A$ and decreasing in $\Omega$. Second, for given $d$, more automation (larger $A$ ) has two opposite effects on match surplus for $d \in[0, F(1+\Omega) / \gamma A]$ : a positive effect working through $A^{\frac{1}{1-\beta}}$ ('productivity effect') and a negative one working through $A$ ('mismatch effect'). The sign of the net effect depends on mismatch $d$ :

$$
\frac{d s(d)}{d A}=\underbrace{\frac{\Phi}{2} \frac{1}{1-\beta} A^{\frac{\beta}{1-\beta}}(1-\Omega)[F(1+\Omega)-\gamma A d]}_{\text {productivity effect }}-\underbrace{\frac{\Phi}{2} A^{\frac{1}{1-\beta}}(1-\Omega) \gamma d}_{\text {mismatch effect }},
$$

which shows that automation increases the surplus of good matches (small $d$ ) and decreases the surplus of bad matches (large $d$ ). Third, for given $d$, more offshoring (larger $\Omega$ ) also has two opposite effects on match surplus for $d \in[0, F(1+\Omega) / \gamma A]$ : a positive effect working through $(1+\Omega)$ ('specialization effect') and a negative one working through $(1-\Omega)$ 
('substitution effect'). The sign of the net effect again depends on mismatch $d$ :

$$
\frac{d s(d)}{d \Omega}=\underbrace{\frac{\Phi}{2} A^{\frac{1}{1-\beta}}(1-\Omega) F}_{\text {specialization effect }}-\underbrace{\frac{\Phi}{2} A^{\frac{1}{1-\beta}}[F(1+\Omega)-\gamma A d]}_{\text {substitution effect }} .
$$

However, differently from automation, more offshoring increases the surplus of bad matches (large $d$ ) and decreases the surplus of good matches (small $d$ ). Fourth, match surplus $s(d)$ is log-submodular in $d$ and $A$ as well as log-supermodular in $d$ and $\Omega .{ }^{16}$ In words, better matches (i.e. matches with smaller $d$ ) have a comparative advantage in exploiting automation whereas worse matches (i.e. matches with larger $d$ ) have a comparative advantage in exploiting offshoring.

The log-submodularity of $s(d)$ in $d$ and $A$ derives from the fact that, as $A$ grows, less-thanideal skills or tasks become less substitutable with the corresponding ideal ones that define firms' and workers' 'core competencies'. For this reason, we can use the term 'core-biased technological change' (CBTC) to label the way in which the state of technology evolves in our model. This is different from the concepts of 'routine-biased technological change' and 'skill-biased technological change' previously examined in the literature as discussed in the Introduction.

\subsection{Search and Match}

Due to search frictions, domestic firms and workers are not necessarily all paired in a productive match. Firms can be either producing, labeled by $P$, or vacant, labelled by $V$. Workers can be either employed, labelled by $E$, or unemployed, labelled by $U$. By definition, the sum of employed and unemployed workers equals the labour force, $E+U=L$ and we set $L=1$ by choice of units. Hence, $E+U=1$ holds both in the aggregate and for each address.

Only vacant firms and unemployed workers engage in search. Meeting rates are set according to a standard random search setup featuring Poisson distributed meeting intervals. We adopt a linear matching technology described by a homogeneous-of-degree-one Cobb-Douglas matching function $M(U, V)=\vartheta U^{\xi} V^{1-\xi}$, where $\vartheta$ is matching efficiency, $U$ is unemployment, $V$ are vacancies and $\xi \in(0,1)$ is the elasticity of new matches to unemployment. ${ }^{17}$ In this setup the Poisson arrival rate can be derived as a function of aggregate

\footnotetext{
${ }^{16}$ Making the dependence of match surplus on the relevant parameter explicit, $s(d, A)$ is log-submodular in $d$ and $A$ as, for all $d^{\prime}>d$ and $A^{\prime}>A$, we have $s\left(d^{\prime}, A^{\prime}\right) / s\left(d, A^{\prime}\right)<s\left(d^{\prime}, A\right) / s(d, A)$ or equivalently $\left(d^{\prime}-d\right)\left(A^{\prime}-A\right)<0$. Analogously, $s(d, \Omega)$ is log-supermodular in $d$ and $\Omega$ as, for all $d^{\prime}>d$ and $\Omega^{\prime}>\Omega$, we have $s\left(d^{\prime}, \Omega^{\prime}\right) / s\left(d, \Omega^{\prime}\right)>s\left(\Omega^{\prime}, A\right) / s(\Omega, A)$ or equivalently $\left(d^{\prime}-d\right)\left(\Omega^{\prime}-\Omega\right)>0$.

${ }^{17}$ See Mortensen and Pissarides (1994). Our assumption departs from the non-linear matching function employed in models with two-sided heterogeneity à la Shimer and Smith (2000). In particular, our matching technology implies that congestion externalities arise for each task.
} 
labor market tightness $V / U$. We can then define $q_{v}=M(U, V) / V=\vartheta(U / V)^{\xi}$ as the rate at which vacant firms meet unemployed workers and $q_{u}=M(U, V) / U=\vartheta(V / U)^{1-\xi}$ as the rate at which unemployed workers meet vacancies.

Firms face a cost $c>0$ of maintaining a job either filled or vacant paid in units of the final good. Match surplus is shared according to the Nash bargaining solution with worker bargaining weight $\alpha \in(0,1) .{ }^{18}$ We impose zero outside options for both workers and firms by normalizing the unemployed workers' and vacant firms' income to $0 .{ }^{19}$

Once matched, workers and firms decide whether to produce by comparing their shares of the match surplus with their outside options. Given the Nash bargaining protocol, riskneutrality and zero outside option, workers of type $x$ accept a job of type $y$ if and only if

$$
\Lambda(x)=\{y: S(x, y) \geq 0\}
$$

holds, where $S(x, y)$ is the surplus of the match $(x, y)$, while $\Lambda(x)$ defines the workers' acceptance set. Firms have a similarly defined acceptance set

$$
\Phi(y)=\{x: S(x, y) \geq 0\}
$$

Given the two acceptance sets, the joint matching set $\Lambda(x) \cap \Phi(y)$ evaluates to

$$
M(x, y)=\{x, y: S(x, y) \geq 0\}
$$

All sets are Borel measurable and depend also on automation $A$ and offshoring $\Omega$. Matches can be destroyed by separation shocks, which we assume to happen with per-period probability $\delta \in(0,1)$.

We restrict our attention to acceptance sets featuring positive assortative matching with uniformly distributed workers $x$ and thus also uniformly distributed firms $y .{ }^{20}$ This case has the following appealing features from an analytical point of view. The values of unemployment and vacancies are identical for all workers' and firms' addresses respectively. The values of employment and production depend on distance $d$ only. Also the Nash bargained wage $w(d)$ depends only on $d$. Workers and firms accept matches at some endogenously determined common maximum distance $d^{*}$ from their address. This implies that we can write the acceptance sets for workers as

$$
\Lambda(x)=\left[y-d^{*}, y+d^{*}\right]
$$

\footnotetext{
${ }^{18}$ We could consider alternative wage protocols, such as sequential auctions à la Postel-Vinay and Robin (2002) or Lise and Robin (2017), or also other competiitve wage protocols like in Moen (1997). However, for the purpose of our study, a simple rent sharing rule is appropriate.

${ }^{19}$ If the outside option were positive workers would search for longer.

${ }^{20}$ See Lemma 1 in Marimon and Zilibotti (1999).
} 
and for firms as

$$
\Phi(y)=\left[x-d^{*}, x+d^{*}\right]
$$

\subsection{Value Functions and Nash Bargaining}

A worker's discounted value of being employed $v_{e}(d)$ equals the current wage plus the option value of the potential future loss from unemployment:

$$
\rho v_{e}(d)=w(d)-\delta\left(v_{e}(d)-v_{u}\right)
$$

Analogously, given that unemployed workers' income is normalized to 0, a worker's discounted value of being unemployed $v_{u}$ equals the option value of the potential future gain from employment:

$$
\rho v_{u}=2 q_{u} \int_{0}^{d^{*}}\left(v_{e}(z)-v_{u}\right) d z
$$

which takes into account that an unemployed worker meets a vacancy at endogenous rate $q_{u}$ and converts the meeting into a job if the worker's type falls in the matching set of measure $2 d^{*}$ centered at $d=0$.

Next, the discounted value of a filled vacancy $v_{p}(d)$ equals what is left of the match surplus after the wage $w(d)$ and the maintenance cost $c$ have been paid plus the option value of the potential future loss from exogenous separation at rate $\delta$ :

$$
\rho v_{p}(d)=(s(d)-w(d)-c)-\delta\left(v_{p}(d)-v_{v}\right)
$$

Finally, the value of an unfilled vacancy $v_{v}$ satisfies

$$
\rho v_{v}=-c+2 q_{v} \int_{0}^{d^{*}}\left(v_{p}(z)-v_{v}\right) d z
$$

where the right hand side corresponds to the option value of filling the vacancy at endogenous rate $q_{v}$ in the future net of the maintenance cost $c$.

The set of equilibrium conditions is then completed by the Nash bargaining rule

$$
(1-\alpha)\left(v_{e}(d)-v_{u}\right)=\alpha\left(v_{p}(d)-v_{v}\right)
$$

the free entry condition for the value of a vacancy

$$
v_{v}=0
$$


the zero cutoff value condition for a filled vacancy associated with maximum mismatch $d^{*}$

$$
v_{p}\left(d^{*}\right)=0
$$

and the steady state flow condition for employment

$$
q_{u}=\frac{\delta E}{2 d^{*}(1-E)} .
$$

Condition (20) requires job distruction $\delta E$ to be exactly offset by job creation $2 q_{u} d^{*}(1-E)$ as an unemployed worker meets a vacancy at rate $q_{u}$ and matches with the corresponding firm at a rate given by the ratio between the measures of the matching set (equal to $2 d^{*}$ ) and of the characteristic space (equal to 1 ).

\subsection{Employment, Wages and Selectivity}

By substitution into (18) and (19) the set of equilibrium conditions can be reduced to a system of the two equations

$$
(1-\alpha) \frac{2 \vartheta^{\frac{1}{1-\xi}}\left(q_{u}\right)^{-\frac{\xi}{1-\xi}}}{\delta+\rho+2(1-\alpha) \vartheta^{\frac{1}{1-\xi}}\left(q_{u}\right)^{-\frac{\xi}{1-\xi}}+2 \alpha q_{u}} \int_{0}^{d^{*}} s(z) d z=c
$$

and

$$
(1-\alpha) \frac{\delta+\rho+2 \vartheta^{\frac{1}{1-\xi}}\left(q_{u}\right)^{-\frac{\xi}{1-\xi}}}{\delta+\rho+2(1-\alpha) \vartheta^{\frac{1}{1-\xi}}\left(q_{u}\right)^{-\frac{\xi}{1-\xi}}+2 \alpha q_{u}} s\left(d^{*}\right)=c,
$$

in unknown employment $E$ and maximum mismatch $d^{*}$ with match surplus $s(d)$ and meeting rate $q_{u}$ given by (7) and (20) respectively. ${ }^{21}$ Solving this system gives the equilibrium values of $E$ and $d^{*}$, which can then be used to evaluate the equilibrium wage of domestic workers as follows:

$$
w(d)=\frac{\alpha\left(\delta+\rho+2 q_{u}\right)}{\delta+\rho+2(1-\alpha) \vartheta^{\frac{1}{1-\xi}}\left(q_{u}\right)^{-\frac{\xi}{1-\xi}}+2 \alpha q_{u}} s(d) .
$$

While the equilibrium system is not amenable to closed-form solution, its comparative statics with respect to automation and offshoring are intuitive and can be readily investigated numerically. Figures 1 to 3 provide graphical representations for standard parameter values drawn from the literature that deliver empirically relevant rates of employment and unemployment. $^{22}$

Figure 1 shows the effects of automation on employment (left panel) and 'selectivity' (right panel) for different degrees of offshoring. Analogously, Figure 2 shows the effects of

\footnotetext{
${ }^{21}$ See Appendix $\mathrm{C}$ for detailed derivations.

${ }^{22}$ See Appendix D for additional details.
} 
offshoring on employment (left panel) and 'selectivity' (right panel) for different degrees of automation. 'Selectivity' is measured as $1 / d^{*}$ : more (less) selectivity means that firms and workers are willing to accept less (more) mismatch $d^{*}$ between their skills and tasks. This notion will come handy in the empirical analysis. These figures show that, for the chosen parameter values, equilibrium employment $E$ is a non-monotone function of automation $A$ (Figure 1, left panel) or offshoring (Figure 2, left panel), increasing for small $A$ or $\Omega$ and decreasing for large $A$ or $\Omega$. This non-monotonicity of employment results from the changing balance of the opposite productivity and mismatch or specialization and substitution effects discussed above. However, whereas selectivity increases with automation (Figure 1, right panel), it decreases with offshoring (Figure 2, right panel). As for interactions, the left panel of Figure 1 shows that automation has a weaker positive (stronger negative) impact on employment for small (large) $A$ when there is more offshoring (i.e. for larger $\Omega$ ). Vice versa, the left panel of Figure 2 shows that offshoring has a stronger positive impact on employment for small $\Omega$ but a weaker negative effect on employment for large $\Omega$ when there is more automation (i.e. for larger $A$ ).

Figure 3 depicts the effects of automation and offshoring on wages corresponding to the effects on employment and selectivity reported in Figure 1 and 2 respectively. Figure 3 shows that automation increases wage inequality between the best and worst matches, especially when offshoring is limited. Vice versa, offshoring reduces wage inequality between the best and worst matches, especially when automation is pronounced. While these results on wages are interesting as they speak to the debate on inequality, we do not emphasize them here as our dataset does not allow to test their empirical relevance.

To summarize, for standard parameter values drawn from the literature, in our model automation can have a detrimental impact on employment through a selectivity channel as less-than-ideal 'non-core' tasks/skills become less substitutable with ideal 'core' ones. This is due to the fact that better matches between firms and workers have a comparative advantage in exploiting new technologies. In the case of offshoring, the selectivity channel can work in the opposite direction as less-than-ideal 'non-core' tasks/skills become more substitutable with ideal 'core' ones. This is due to the fact that worse matches between firms and workers have a comparative advantage in exploiting the international decoupling of subtasks. It then remains an empirical question whether this new channel has any practical relevance, and is strong enough to alter the traditional neoclassical conclusions.

\section{Empirical Evidence from Occupational Data.}

To investigate whether our selectivity channel operates in practice, we capture firms' and workers' match selectivity in terms of the concentration of occupations' employment across 
sectors. In the wake of Costinot and Vogel (2010) the underlying idea is that, while a sector may cover a rich menu of occupations, these include a submenu of 'core' occupations that are disproportionately concentrated in the sector. In this respect, an increase in the concentration of occupations' employment across sectors can be interpreted as an increase in match selectivity. We then study the effects of automation and offshoring on employment channeled through the sectoral concentration of occupations' employment. While for simplicity our theoretical model assumes perfect symmetry across skills and tasks, our empirical set-up will allow for more flexibility in exploiting the heterogeneity of observed patterns across countries, sectors and occupations.

We will proceed as follows. After introducing our dataset (Section 3.1) and reporting some descriptive statistics (Section 3.2), we will estimate the effects of automation and offshoring on occupational employment channeled through selectivity (Section 3.3). We will then offer a simple assessment of the contribution of the selectivity channel to the total effect of automation on employment (Section 3.4). Finally, we will draw conclusions about aggregate employment effects with an emphasis on automation as this has attracted much attention in recent years (Section 3.5).

\subsection{Data and Variables}

We use sectoral and occupational level data on European countries extracted from the European Labour Force Survey (hereafter EULFS). We restrict our analysis to the years 1995 - 2010 in order to include the maximum number of available countries and keep a consistent classification of occupations. We aggregate worker-level observations into country $\times$ sector $\times$ occupation $\times$ year cells to analyze country, sectoral and occupational heterogeneities. We exploit long-differences between 1995 and 2010 assuming that automation and offshoring shocks materialize between these two dates as documented in other studies. ${ }^{23}$ For the remainder of the paper, the long-difference of any variable $Y$ between 1995 and 2010 will be simply denoted $\Delta Y$. We focus on 92 occupations at the 3-digits ISCO-88 level and 16 sectors according to the NACE Rev.2 classification. To ensure the stability of the sector definition across years, we group these 16 sectors into 11 sectors. ${ }^{24}$ We analyse data from 13 countries, both Anglo-Saxon and continental European, in order to make results

\footnotetext{
${ }^{23}$ For instance, Chiacchio, Petropoulos and Pichler (2018) shows that robot penetration in the EU28 has tripled over this period and particularly between 1995-2007 relative to the years 2007-2015. A similar pattern can be observed for offshoring as measured by foreign direct investment and intermediates trade in the WTO and UNCTAD statistics.

${ }^{24}$ Following Goos, Manning and Salomons (2014), occupations and sectors closely associated with public and agricultural activities are dropped. We also drop 3-digit ISCO occupations that are not precisely reported. These occupations are dropped from the final sample. This corresponds to $1.1 \%$ of total hours worked in the sample and this only affects 6 countries in the sample.
} 
robust to local institutions or cultural trends. ${ }^{25}$ For each country, sector and occupation we have information on employment, number of employees, number of hours worked, number of unemployed workers (see Appendix A for more details on the data).

We merge these data with indices capturing occupations' exposure to automation ('automatability') and to offshoring ('offshorability'). We use these indices to infer actual automation and offshoring in the subsequent years, which we do not observe. The underlying idea here is that automation and offshoring are two general long-run trends whose effects can be assessed in terms of the differential exposure of different occupations to them.

To measure the 'automatability' of an occupation we use the Routine Task Intensity index (RTI) as computed by Acemoglu and Autor (2011), which has been widely used in previous studies (see among many others Autor, Levy and Murnane, 2003; Autor and Dorn, 2013; Goos, Manning and Salomons, 2014). ${ }^{26}$ The RTI builds on information about the task content of occupations available from the U.S. Dictionary of Occupational Titles (DOT). We use a crosswalk to go from the SOC 2000 classification used in DOT to the 4-digits ISCO-88 classification before aggregating to the 3-digit ISCO-88 classification (see Appendix A for additional details). Comparing our RTI measure with an alternative measure of automatibility constructed by Frey and Osbourne (2013) reveals a large positive correlation between them with only few exceptions for specific occupations. ${ }^{27}$ As for 'offshorability', we adopt the index developed by Blinder and Krueger (2013) (hereafter BK). The index builds on questionnaires as well as qualitative observations and is constructed by professional coders based on an occupational classification of workers. Offshorabilty is then reported on a 4-step qualitative scale from Highly Non Offshorable (1) to Highly Offshorable (4). ${ }^{28}$ A different measure is provided by Acemoglu and Autor (2011), who instead build a quantitative index based on aggregating several ONET indicators. While correlations between these different measures are mostly positive (see Appendix A for additional details), we use the BK index as our benchmark measure of offshorability as Goos, Manning and Salomons (2014) find that this index is more reliable when compared with actual offshoring measures. ${ }^{29}$

\footnotetext{
${ }^{25}$ These countries are Austria, Belgium, Germany, Denmark, Spain, France, United Kingdom, Greece, Ireland, Italy, Luxembourg, Netherlands, Portugal. For these countries full time coverage is available.

${ }^{26} \mathrm{We}$ adopt the definition of Lewandowski et al. (2017): $R T I_{o}=\ln$ (Routine Cognitive $_{o}+$ ${\left.\text { Routine } \text { Manual }_{o}\right)-\ln (\text { Non-Routine Analytical }}_{o}+$ Non-Routine Interpersonnal $\left._{o}\right)$. Throughout we standardize RTI to have a mean equal to zero and a standard deviation of one.

${ }^{27}$ The measure used by Frey and Osbourne (2013) builds on the selection of solutions that engineers need to devise for specific occupations to be automated and is given by the probability of computerization based on a Gaussian process classifier.

${ }^{28}$ The index of Blinder (2009) is constructed in the same way, but it reports a qualitative ranking of occupations according to their degree of offshorability.

${ }^{29}$ We obtain data from the Princeton Data Improvement Initiative (https://krueger.princeton.edu/ pages/princeton-data-improvement-initiative-pdii). The matching procedure of occupations with our automatability and offshorability indices is detailed in Appendix A.
} 
While both automation and offshoring may displace workers, it is important to note that they are conceptually quite different as stressed in our theory section. The likelihood of automation is linked to the routineness of a task, hence to the possibility that it can be solved algorithmically by a computer or a robot. Differently offshorability à la BK refers to the ability to perform one's work duties, for the same employer and customers, in a foreign country, even though the supply of the good or the service is still based in the home market. Accordingly, while the correlation between our measures of automatability and offshorability is positive, there are important exceptions across occupations (see column 4 and 5 in Table 1 and Appendix A for a full picture).

We operationalize match selectivity as the concentration of occupations' employment across sectors as follows. Let $\mathcal{O}=\left\{o_{1}, \ldots, o_{92}\right\}$ be the set of occupations, $\mathcal{K}=\left\{k_{1}, \ldots, k_{11}\right\}$ be the set of sectors and $\mathcal{I}=\left\{i_{1}, \ldots, i_{13}\right\}$ be the set of countries in our sample. Consider occupation $o \in \mathcal{O}$ in sector $k \in \mathcal{K}$ of country $i \in \mathcal{I}$ with employment denoted by $L_{\text {oki }}$. Our measure of occupation $o$ 's employment concentration across sectors $k \in \mathcal{K}$ in country $i$ is given by the Herfindhal index

$$
S S O_{o i}=\sum_{k \in \mathcal{K}}\left(\frac{L_{o k i}}{\sum_{k \in \mathcal{K}} L_{o k i}}\right)^{2}
$$

where 'SSO' is a mnemonic for 'sectoral selectivity of occupation'. Two remarks on (24) are in order. First, as each occupation is not present in every sector, a key feature of our selectivity index is that it is not standardized to account for the number of sectors used in the estimation. To understand this point, assume, for instance, that an occupation is equally observed in 5 different sectors in 1995, but disappears from one of the sectors in 2010 with previous employment from this sector evenly reallocated to the other four sectors. The distribution of the occupation's employment across sectors is, therefore, uniform both in 1995 and in 2010. A standardized Herfindahl index would be equal to zero in both cases, implying that no change in selectivity is detected between 1995 and 2010 for this occupation. It is, however, key to our identification strategy that a positive change in selectivity is detected in this case as the occupation's employment is actually more concentrated across sectors in 2010 than in 1995. Second, high (low) SSO implies that few (many) sectors account for a large share of the occupation's employment. As SSO is thus inversely related to the size of the theoretical matching set ('mismatch'), we will investigate the robustness of our findings based on SSO exploiting two traditional measures of mismatch: unemployment duration and education-based metrics of skill mismatch. 


\subsection{Descriptive Statistics}

Table 1 presents descriptive statistics on the occupational characteristics aggregated at the 2-digit level for clarity. Occupations are ranked from the least to the most routine-intensive. Column 1 displays the percentage point change in the share of hours worked between 1995 and 2010. Overall the change is smaller (or negative) for occupations that are more 'automatable' (i.e. routine-intensive). Among the ten most routine-intensive occupations only Customer Service Clerks (42) and Sales and Services Elementary (91) do not exhibit a fall in the share of hours. Column 2 reports the change in unemployment. For eight out of the ten least routine-intensive occupations the unemployment rate between 1995 and 2010 drops. It is, however, worth noting that for half of the ten most routine-intensive occupations we observe falling or relatively stable unemployment rates.

Figure 4 presents further preliminary evidence - similar to Figure 1 - on the direct effects of automatability on employment and its interplay with offshorability. We collapse observations to the occupation level and divide the 92 occupations into two groups according to median offshorability. ${ }^{30}$ Overall (dashed line) occupations that had a low (high) share of routine-intensive tasks in 1995 experience an increase (decrease) in total hours worked in the subsequent years as employment shifts from routine to non-routine occupations. When considering the interaction with offshorability, a more nuanced pattern emerges: while the negative relationship between routine-intensity and employment is confirmed for highly offshorable occupations (solid black line), the observed change in hours worked in occupations with low offshorability (solid grey line) is unrelated to the routine-intensity of tasks performed in this occupation.

\subsection{Selectivity and Employment}

We assess the effects of automation and offshoring on employment channeled through selectivity in two steps. First, considering automation and offshoring as two general long-run trends to which different occupations are differentially exposed, we regress SSO on automatability and offshorabilty while including country-specific time trends. We find that selectivity increases more in occupations with high automatability while it falls in occupations with high offshorability. Second, we regress employment on SSO, finding a negative relation between employment and selectivity. Using a double-Bartik instrument (see Chodorow-Reich and Wieland, forthcoming), we show that this relation is associated with a causal negative impact of selectivity on employment.

\footnotetext{
${ }^{30}$ We aggregate our data at the cell level $($ country $\times$ sector $\times$ occupation $\times$ year) into occupation $\times$ year cells and compute the log change in hours worked across the countries in our sample for each occupation: $\Delta \ln \left(\right.$ Hours $\left._{o}\right)=\ln \left(\right.$ Hours $\left._{o}^{2010}\right)-\ln \left(\right.$ Hours $\left._{o}^{1995}\right)$.
} 


\subsubsection{From Technology to Selectivity}

In the first step we verify whether more automatable and offshorable occupations experience a change in selectivity over the period 1995 - 2010 in line with the predictions of our model. To this end we estimate the following equation:

$$
\Delta \ln \left(S S O_{o i}\right)=\beta_{1} R T I_{o}+\beta_{2} \text { Offshor } \text { sho }^{\prime}+Z_{o i}^{\prime} \mathbf{C}+\mu_{i}+\epsilon_{o i}
$$

where $\operatorname{sln}\left(S S O_{o i}\right)$ is occupation o's change in SSO between 1995 and 2010 in country $i$, $R T I_{o}$ and $O f f s h o r_{o}$ are our indices of automatability and offshorability, and $\mathbf{C}$ is a vector of coefficients associated with a set of control variables $Z_{o i}$. Additionally we include country fixed effects $\left(\mu_{i}\right)$ that account for country-level aggregate trends. The corresponding estimates are reported in Table 2 with country fixed effects displayed in Figure 5. These are positive for all countries $(\min =0.24 ; \max =0.85$; mean $=0.59)$ and positively related to the change in TFP, which supports the interpretation of country fixed effects as manifestations of country-specific aggregate technology trends.

Turning to the other results in Table 2, column 1 shows that, as predicted by the model, occupations with higher initial automatability become more selective. The coefficient is, however, imprecisely estimated. One reason might be that the sample includes a selection of occupations that are hard to automate or not automatable at all, which leads to underestimating the effect of technological change. The effect of offshoring is instead precisely estimated and negative as predicted by the model.

Next we estimate a less restrictive model than the linear specification (Equation (25)), in which we explicitly allow for asymmetric effects between high and low automatability occupations. We do so by defining a dummy variable $I_{o i}^{H}$ for occupation $o$ in country $i$ that takes value one if the occupation's $R T I_{o}$ is above the median $R T I_{o}$ across all occupations in country $i$ and zero otherwise. We then estimate the following specification:

$$
\Delta \ln \left(S S O_{o i}\right)=\beta_{1} R T I_{o} \times I_{o i}^{H}+\beta_{2} R T I_{o} \times I_{o i}^{L}+\beta_{3} \text { Offshor } \text { sho }_{o}+Z_{o i}^{\prime} \mathbf{C}+\mu_{i}+\epsilon_{o i}
$$

with $I_{o i}^{L}=1-I_{o i}^{H}$. Column 2 in Table 2 reports the corresponding results. It shows that occupations at higher risk of automation experience a large significant increase in selectivity between 1995 and 2010, whereas occupations that are harder to automate exhibit no statistically significant change in selectivity. The effect of offshoring is again negative and precisely estimated. As predicted by the model, automation and offshoring have opposite effects on match selectivity. These results remain robust also when we include an interaction term between automatibility and offshorability in column 3. Furthermore the interaction's positive sign is in line with our model though not significant. 
Having established that the main channels of the model are operative in the data, we further refine our empirical analysis. First, we check whether other sources of occupational heterogeneity affect the strength of the selectivity channel by adding an occupation's share of employment in 1995 and its interaction with automatability. In doing so, to maintain the number of estimated parameters at a reasonable level, we return to specification (25). The corresponding results are reported in column 4, which shows that the positive effect of automation on selectivity is largely driven by occupations with larger employment shares.

Second, we assess the relevance of possible general equilibrium or spillover effects. Reallocation, following a potential shock in one occupation, may bias the estimated change in selectivity in other occupations. For example, labor supply in less automatable occupations may be affected by the response of more automatable occupations. In a case like this, the observed change in the selectivity of the former occupations may not be necessarily due to their own automatability, but rather to what is happening to the latter occupations. In this respect, Berg and Streitz (2019) propose a parsimonious way of estimating treatment, spillover and aggregate effects. The method consists of adding an interaction between the variable of interest and its average over the group that may be affected by spillovers. The method is effectively a linear-in-means estimator where spillovers are assumed to vary within the most likely 'spillover dimension' and vary linearly with the average treatment intensity. We adapt their approach, designed for binary treatments, to our continuous measure of automatability. As mobility is typically stronger across occupations than across countries, we take the country as our spillover-sensitive group. We then introduce again our dummy $I_{o i}^{H}$ (which takes value one for occupations above median $R T I_{o}$ and zero otherwise) interacting it with its group-mean $\overline{R T I}_{-o i}$ obtained excluding occupation $o$. Finally, we estimate the following equation:

$$
\Delta \ln \left(S S O_{o i}\right)=\beta_{1} R T I_{o} \times I_{o i}^{H}+\beta_{2} R T I_{o} \times I_{o i}^{L}+\beta_{3} \overline{R T I}_{-o i} \times I_{o i}^{H}+\beta_{4} \overline{R T I}_{-o i} \times I_{o i}^{H}+Z^{\prime} \mathbf{C}+\epsilon_{o i}
$$

where, given mean-linearity, we omit group-level fixed effects as this would bias the estimation. The positive and significant estimate in column 5 confirms the positive effect of automation on selectivity even when controlling for potential spillovers. In fact, it is estimated to be almost twice as large indicating that unmodeled spillovers or general equilibrium effects strengthen the impact of automation on selectivity. On the other hand, the impact of offshoring maintains its significantly negative sign with little change in its absolute value.

Finally, all columns of Table 2 feature initial selectivity in 1995 as an additional control. Its negative and significant coefficient reveals an overall process of convergence towards higher selectivity across all occupations. 


\subsubsection{From Selectivity to Employment}

In the second step we investigate the effects of selectivity on employment through the following specification:

$$
\Delta \ln \left(\text { Hours }_{o i}\right)=\gamma+\delta_{1} \Delta \ln \left(S S O_{o i}\right)+K^{\prime} \mathbf{C}_{2}+\eta_{i}+v_{o i}
$$

where $\Delta \ln \left(\right.$ Hour $\left._{o i}\right)$ is the long difference in total hours worked in occupation $o$ in country $i, \Delta \ln \left(S S O_{o i}\right)$ is the change in selectivity, $K^{\prime}$ a matrix of control variables and $\mathbf{C}_{\mathbf{2}}$ the vector of their coefficients.

An important concern underlying Equation (28) is the potential endogeneity between the changes in our measure of selectivity constructed using employment shares and the changes in hours worked. The sign of the bias is not obvious as it depends on the distribution of occupational employment shares across sectors. We address this concern by using a classical Bartik instrument similar to the 'double-Bartik' instrument proposed by Chodorow-Reich and Wieland (forthcoming). To construct this instrument, we first compute the Bartikpredicted change in employment in an occupation $\times$ industry $\times$ country cell as the employment growth that would prevail if that cell grew at exactly the same rate as in all other countries in our sample. Then, we re-compute our measure of selectivity using the Bartik-predicted employment shares instead of the actual ones. Formally, the predicted employment in 2010 is $\widehat{L_{o i k, 2010}^{b}}=g_{o,-i, k, 2010}^{b} \times s_{o, i, k, 1995}$ where $g_{o-i k, 2010}^{b}$ is the average growth rate of an occupationindustry pair in all other countries of the sample (denoted by the index $-i$ ) and $s_{o i k, 1995}$ is the employment of occupation $o$ in sector $k$ in country $i$ in 1995. The Bartik-predicted SSO in 2010 is given by $\widehat{S O_{o i, 2010}^{b}}=\sum_{k \in \mathcal{K}}\left(\hat{s}_{o i k, 2010}^{b}\right)^{2}$ with $\hat{s}_{o i k, 2010}^{b}$ being the share of predicted employment of occupation $o$ in sector $k$ and country $i$ in 2010. Our instrument is then the log change in predicted SSO:

$$
\Delta \widehat{\ln \left(S S O_{o i}^{b}\right)}=\ln \left(\frac{S \widehat{S O_{o i, 2010}^{b}}}{S S O_{o i, 1995}}\right)
$$

Following the arguments outlined in Chodorow-Reich and Wieland (forthcoming), we include the predicted occupation-industry employment growth $\Delta \ln \left(L^{b}\right)=\ln \left(\frac{L_{o i k, 2010}^{b}}{L_{o i, 1995}}\right)$ as an additional control. This serves the purpose of controlling for unobserved variation due to potential secular trends in occupation-industry employment shares across countries.

Table 3 displays the results for both OLS and IV regressions. For the latter it also reports the first-stage results. The first-stage F-statistic suggests that our instrument is not weak 
and associated first-stage estimates are, as expected, positive and significant. ${ }^{31}$ In column 1 , the OLS regression features a negative and significant coefficient on selectivity. Column 2, which implements our double-Bartik strategy, exhibits a similar negative and significant estimate. Columns 3 and 4 introduce additional controls with OLS and IV respectively. Column 4 shows that further controlling for the direct effects of automatibility and offshorability on employment increases the estimated coefficient on selectivity. The estimated coefficient is still negative, significant and larger than the corresponding OLS estimate in column 3 as well as larger than the corresponding IV estimate in column 2. Controlling for occupation $\times$ country fixed effects with IV in column 5 yields a similar highly significant, negative effect of increased selectivity on employment. After controlling for any occupation-level and country-level shocks, the coefficient of selectivity is almost three times as large in absolute value as the corresponding estimate in column 2. We can thus conclude that selectivity has a significant negative causal effect on employment: increased concentration of an occupation's employment across sectors has caused an employment reduction in that occupation.

We test the robustness of our findings in Table 4. First, in column 1 we restrict the sample only to occupations that experience an increase in selectivity. According to the model, we should expect the effect on employment to materialize especially in these occupations. We find indeed that the estimated coefficient on selectivity in column 1 is negative, statistically significant and larger than the corresponding coefficient estimated on the full sample (column 4 in Table 3). Column 2 shows that the negative impact of selectivity is confirmed when we include occupation-level fixed effects. Next, we allow as before for asymmetric effects by distinguishing between more or less automatable occupations according to country medians and interact this dummy with selectivity. ${ }^{32}$ In Column 3 the inclusion of these interaction terms reveals that the impact of selectivity is mainly driven by highly automatable occupations. Column 4 repeats this exercise for occupations that experience a positive change in selectivity, yielding stronger effects as expected. The inclusion of occupation fixed effects in columns 5 and 6 does not alter the main results.

\subsubsection{Selectivity and Mismatch}

To further investigate the empirical validity of our theoretical mechanism linking automation and offshoring to selectivity, we look at two measures of 'mismatch' from the literature: 'unemployment duration' and 'educational mismatch'.

\footnotetext{
${ }^{31}$ The Kleinberger-Paap F-statistic is large and largely above the Montiel-Pflueger robust weak instrument test critical values (Montiel and Pflueger, 2013; Pflueger and Wang, 2015, for Stata implementation).

${ }^{32}$ In this case the Kleinberger-Paap F statistic falls since we have included a second variable potentially susceptible to endogeneity problems. Nevertheless the first stage F-statistic, shown for columns (3) to (6), is always above the threshold proposed by Stock and Yogo (2002). In our context, this threshold for a maximum bias of $10 \%$ is 7.03 .
} 
Unemployment Duration A key implication of our model is that an increase in the value of ideal matches makes workers and firms search for longer before agreeing to match, which increases unemployment duration. Accordingly, automation raises unemployment duration whereas offshoring should reduces it. Then, unless in the data (differently from the model) all search happens on-the-job, we should be able to observe a positive relation between automation and unemployment duration and a positive relation between offshoring and automation.

To test whether this is indeed the case, we compute unemployment duration based on the occupation and industry of the last job. ${ }^{33}$ Column 1 in Table 5 reports the results obtained by regressing unemployment duration on automation and offshoring. As predicted, the coefficient on automatability is positive and significant. Unemployment duration increases in sectors with higher initial automatability. Though imprecisely estimated, also the coefficients on offshorability and its interaction with automatability have the predicted sign.

Educational Mismatch Our model emphasizes horizontal mismatch as this is its key novelty. Nonetheless, as highlighted in the model's extension in Appendix D, horizontal mismatch should not be seen as alternative but rather as complementary to vertical mismatch. This leads us to use educational mismatch to proxy for the extent to which workers' skills in given occupations are aligned with those occupations' task content. We measure over-education, under-education and educational mismatch (the sum of over- and under-education) by comparing each worker's years of education with those of their peers in a given occupation, sector and country at the time of observation. The worker is overeducated (under-educated) when their educational level is above (below) the average of their 10-year cohort by more than 2 standard deviations (see e.g. Hartog, 2000, for a similar definition). ${ }^{34}$ We then obtain the share of over- and under- educated workers in each occupation $\times$ industry $\times$ country cell.

According to the logic of our model, as automation makes firms more selective while offshoring makes them less selective, we should observe a fall in under-education among matched workers. Results in column 3 of Table 5 confirm this hypothesis: under education falls in more automatable occupations and increases in more offshorable occupations. Consistently with the model the interaction between automation and offshoring is negative. The effect on educational mismatch (column 2) is, instead, ambiguous due to the fact that over-education (column 3) reacts in the opposite direction of under-education. This may be

\footnotetext{
${ }^{33}$ To improve precision given the small number of observations in any cell, we use occupations defined by the 2-digit ISCO classification. Due to data availability constraints, we have to exclude France and Netherlands from this sample.

${ }^{34}$ Again, to improve precision, we aggregate occupations at the 2-digits ISCO level. Due to poor data availability for educational variables before 1998, we start our sample from 1998.
} 
explained by vertical specialization, which biases firms in favor of workers with higher skills along the lines of the model's extension in Appendix D.

\subsection{Core-Biased Technological Change}

The previous section has provided evidence consistent with the existence of what we have called 'core-biased technological change' (CBTC): automation increases match selectivity by making less-than-ideal skills and tasks less substitutable with the ideal ones defining firms' and workers' core competencies. In this section we propose a simple quantification of the contribution of CBTC to the total effect of automation on employment. The contribution is computed by dividing the effect of RTI-based selectivity on hours worked (CBTC) by the total effect of RTI on hours worked.

First, from Equation (26) we obtain the contribution of automation to the change in selectivity as $\Delta^{\mathrm{RTI} \text { on SSO }}=\hat{\beta}_{1} R T I_{o i} \times I_{o i}^{H}$. We focus on high-automatability occupations as we have found no significant effect for low-automatability ones. From Equation (28) we obtain the impact of the change in selectivity on the change in hours worked as $\hat{\delta}_{1} \Delta \ln \left(S S O_{o i}\right)$. We then compute the contribution of automation to the change in employment as $\Delta^{\text {RTI-based SSO }}=\hat{\delta}_{1} \Delta^{\text {RTI on SSO }}=\hat{\delta}_{1} \hat{\beta}_{1} R T I_{o i} \times I_{o i}^{H}$. Next, we estimate the following equation to extract the direct (local) effect of automation on hours worked:

$$
\Delta \ln \left(\text { Hour }_{o i}\right)=\zeta_{1} R T I_{o} \times I_{o i}^{H}+\zeta_{2} R T I_{o} \times I_{o i}^{L}+\zeta_{3} \text { Offshor }{ }_{o}+\xi_{i}+\xi_{o}+\Upsilon_{o i},
$$

where $\xi_{i}$ and $\xi_{o}$ are country and occupation fixed effects respectively. The total effect of automation is given by $\Delta^{t o t}=\widehat{\zeta}_{1} R T I_{o i} \times I_{o i}^{H}$ with estimated $\widehat{\zeta}_{1}=-0.443(p<0.01)$.

The estimated contribution of CBTC to the total change in employment due to automation is then given by:

$$
\frac{\Delta^{\text {RTI-based SSO }}}{\Delta^{t o t}}=\frac{\hat{\delta_{1}} \times \hat{\beta}_{1}\left(R T I_{o} \times I_{o i}^{H}\right)}{\hat{\zeta}_{1} R T I \times I_{o i}^{H}}=\frac{\hat{\delta_{1}} \times \hat{\beta}_{1}}{\hat{\zeta}_{1}}=\frac{0.207 \times(-0.343)}{(-0.445)}=0.160,
$$

which implies that, for high automatability occupations, the change in employment due to CBTC corresponds to $16 \%$ of the total direct change in employment from 1995 to 2010.

\subsection{Aggregate effects}

We conclude our empirical analysis by giving an indication of the relevance of the selectivity channel for the impact of automation on aggregate employment. Estimating this impact is difficult as it requires accounting for general equilibrium effects that are often ignored in the literature (Chodorow-Reich, Forthcoming). A way to deal with them is through structural 
approaches such as those in Acemoglu and Restrepo (2018b), Chiacchio, Petropoulos and Pichler (2018), Autor and Salomons (2018) and Gregory, Salomons and Zierahn (2018). Structural approaches, however, although conditioned by micro-econometric estimates, rely heavily on the model structure. Another way to deal with general equilibrium effects is through reduced form estimates of aggregate effects. These usually estimate treatment effects at the disaggregated level, then rely on regressions at the aggregate level and their differences from disaggregated results to gain insight into general equilibrium 'spillovers'. We follow the methodology proposed by Berg and Streitz (2019), which allows us to directly estimate the general equilibrium effects based on a simple aggregation of our econometric estimates at the occupation-level.

The underlying logic can be explained through a simple example. Consider two countries, each with two potentially different occupations. Workers are mobile between occupations in the same country, but not between countries. Suppose first that in one of the two countries an occupation is hit by an automation shock such that some jobs in that occupation vanish. As workers are released from the occupation, labor supply increases and wages fall for the other occupation. This way the shock to the former occupation has spillover effects on the latter occupation. The strength of the spillover effects depend on the share of treated occupations, which in this case is 0.5. Now suppose instead that, rather than having half of the occupations in a country hit by an automation shock, all occupations in that country (i.e. in half of the countries) are affected. In this case the fraction of treated occupations is 1 in the affected country and 0 in the other, and thus for both countries spillovers are immaterial when it comes to estimating the shock's general equilibrium effects.

To leverage the type of difference exemplified by this example's two cases, we follow Berg and Streitz (2019) in introducing an interaction between the variable of interest and its average over the group that may be affected by spillovers. In particular, we estimate the following equation at the occupation $\times$ country level:

$$
\Delta \ln (\text { Hours })_{o i}=\beta_{0}+\beta_{1} I_{o}^{H}+\beta_{T} \overline{R T I}_{-o i} I_{o}^{H}+\beta_{C} \overline{R T I}_{-o i} I_{o}^{L}+\epsilon_{o i} .
$$

This corresponds effectively to (27) directly estimated on the change in employment, where as before we adapt our continuous RTI index to the setting of binary treatment. We then compute the aggregate country-specific effect of automation as:

$$
E\left[{\overline{\Delta l n(\text { Hours })_{i}}}_{i} \mid \overline{R T I}_{i}\right]=\beta_{0}+\left(\beta_{1}+\beta_{C}\right){\overline{R T I_{i}}}+\left(\beta_{T}-\beta_{C}\right){\overline{R T I_{i}}}^{2},
$$

where $\overline{R T I}_{i}$ is computed averaging $\overline{R T I}_{-o i}$ across occupations.

The cross-country results for (29) are reported along the vertical axis of Figure 6 with around a third of countries exhibiting negative aggregate employment effects and two thirds 
exhibiting positive effects. The interpretation of these results is complicated by the fact that the RTI index captures the probability of an occupation to be automated while it is actual automation that matters for the computation of aggregate effects. Hence it is helpful to put the estimated aggregate effects in context by comparing them with the observed changes in TFP from 1995 to $2010 .^{35}$ Our model implies that productivity gains due to automation should be accompanied by changes in selectivity and employment also at the aggregate level controlling for general equilibrium effects. The signs of these changes depend on parameter values that affect the balance between the 'productivity effect' and the 'mismatch effect' of automation. Figure 6 therefore plots (29) against the change in TFP across countries. This reveals an overall negative relation between the estimated aggregate employment effects of automatability and TFP growth, which is consistent with the relevance of the selectivity channel also at the aggregate level despite the fact that the majority of countries experience increased employment during the period of observation.

\section{Conclusion}

There are growing concerns about the negative impacts of automation and offshoring on employment and wage inequality. As long as both phenomena are to be interpreted as technological changes, traditional neoclassical arguments imply that those concerns are unfounded. They also imply that both phenomena have ultimately the same effects on employment and wage inequality. We have shown, theoretically and empirically, that the effects of technological change on the labor market can substantially deviate from standard neoclassical conclusions when search frictions hinder efficient assortative matching between firms with heterogeneous tasks and workers with heterogeneous skills.

We have modeled automation as an increase in the productivity of any given match ('productivity effect'), but also as an increase in the productivity of ideal matches relative to less-than-ideal ones ('mismatch effect'). In parallel, we have modeled offshoring as an increase in the productivity of any given match thanks to domestic workers' subtask specialization ('specialization effect'), but also as a decrease in the subset of subtasks assigned to them ('substitution effect'). While the productivity and specialization effects of automation and offshoring increase the match surplus of domestic firms and workers, their mismatch and substitution effects work in the opposite direction.

Our key hypothesis is that better matches enjoy a comparative advantage in exploiting automation and a comparative disadvantage in exploiting offshoring. It implies that

\footnotetext{
${ }^{35}$ This follows in spirit Autor and Salomons (2018) who consider TFP as an "omnibus measure of technological change". Of course TFP is only an imperfect measure for the realized productivity gains due to automation.
} 
automation (offshoring) may reduce (raises) employment by lengthening (shortening) unemployment duration due to higher (lower) match selectivity. We find empirical support to this implication in a dataset covering 92 occupations and 16 sectors in 13 European countries from 1995 to 2010. This evidence is consistent with the existence of what we have called 'core-biased technological change' (CBTC): automation increases match selectivity by making less-than-ideal skills and tasks less substitutable with the ideal ones defining firms' and workers' core competencies. 


\section{References}

Acemoglu, Daron, and David H. Autor. 2011. "Skills, Tasks and Technologies: Implications for Employment and Earnings." Handbook of Labor Economics.

Acemoglu, Daron, and Fabrizio Zilibotti. 2001. "Productivity Differences." The Quarterly Journal of Economics, 116(2): 563-606.

Acemoglu, Daron, and Pascual Restrepo. 2018a. "Artificial Intelligence, Automation and Work." NBER Working Paper.

Acemoglu, Daron, and Pascual Restrepo. 2018b. "The Race between Man and Machine: Implications of Technology for Growth, Factor Shares, and Employment." American Economic Review, 108(6): 1488-1542.

Acemoglu, Daron, and Pascual Restrepo. 2020. "Robots and Jobs: Evidence from US labor markets." Journal of Political Economy, 128(6): 000-000.

Aghion, Phillipe, Benjamin F. Jones, and Charles I. Jones. 2017. "Artificial Intelligence and Economic Growth." NBER Working Paper.

Akst, Daniel. 2013. "What can we learn from the Anxiety over Automation?" Wilson Quarterly.

Arkolakis, Costas, Natalia Ramondo, Andrés Rodríguez-Clare, and Stephen Yeaple. 2018. "Innovation and Production in the Global Economy." American Economic Review, 108(8): 2128-73.

Autor, David, and Anna Salomons. 2018. "Is Automation Labor-Displacing? Productivity Growth, Employment, and the Labor Share." NBER Working Paper, , (24871).

Autor, David H. 2015. "Why Are There Still So Many Jobs? The History and Future of Workplace Automation." Journal of Economic Perspectives, 29(3): 3-30.

Autor, David H., and David Dorn. 2009. "This Job is "Getting Old": Measuring Changes in Job Opportunities using Occupational Age Structure." American Economic Review, 99(2): 45-51.

Autor, David H., and David Dorn. 2013. "The Growth of Low-Skill Service Jobs and the Polarization of the US Labor Market." American Economic Review, 103(5): 1553-1597.

Autor, David H., David Dorn, and Gordon H. Hanson. 2013. "The Geography of Trade and Technology Shocks in the United States." American Economic Review, 103(3): 220-25.

Autor, David H, David Dorn, and Gordon H Hanson. 2015. "Untangling Trade and Technology: Evidence from Local Labour Markets." The Economic Journal, 125(584): 621-646. 
Autor, David H., Frank Levy, and Richard J. Murnane. 2003. "The Skill Content of Recent Technological Change: An Empirical Exploration." The Quarterly Journal of Economics, 118(4): 1279-1333.

Bartel, Ann, Casey Ichniowski, and Kathryn Shaw. 2007. "How Does Information Technology Affect Productivity? Plant-Level Comparisons of Product Innovation, Process Improvement, and Worker Skills." The Quarterly Journal of Economics, 122(4): 17211758.

Becker, Gary S. 1974. "A Theory of Marriage: Part II." Journal of Political Economy, 82(2): 11-26.

Berg, Tobias, and Daniel Streitz. 2019. "Handling Spillover Effects in Empirical Research." Working Paper.

Blinder, Alan S. 2009. "How many US Jobs might be Offshorable?" World Economics, 10(2): 41-78.

Blinder, Alan S., and Alan B. Krueger. 2013. "Alternative Measures of Offshorability: A Survey Approach." Journal of Labor Economics, 31(1): 97-128.

Bostrom, Nick. 2014. Superintelligence: Paths, Dangers, Strategies. Oxford University Press.

Bowen, H.R. 1966. "Report of the National Commission on technology, Automation and Economic Progress: Volume I." U.S. Government Printing Office, Washington.

Brynjolfsson, Erik, and Andrew McAfee. 2014. The Second Machine Age: Work, Progress, and Prosperity in a Time of Brilliant Technologies. W. W. Norton Company.

Caselli, Francesco, and Alan Manning. 2019. "Robot Arithmetic: New Technology and Wages." American Economic Review: Insights, 1(1): 1-12.

Cedefop Eurofound. 2018. "Insights into skill shortages and skill mismatch: Learning from Cedefop's European skills and jobs survey." Cedefop Reference Series, 106.

Chiacchio, Francesco, Georgios Petropoulos, and David Pichler. 2018. "The Impact of Industrial Robots on EU Employment and Wages: A Local Labour Market Approach." Bruegel Working Papers.

Chodorow-Reich, Gabriel. Forthcoming. "Regional Data in Macroeconomics: Some Advice for Practitioners." Journal of Economic Dynamics and Control.

Chodorow-Reich, Gabriel, and Johannes Wieland. forthcoming. "Secular Labor Reallocation and Business Cycles." Journal of Political Economy.

Costinot, Arnaud, and Jonathan Vogel. 2010. "Matching and Inequality in the World Economy." Journal of Political Economy, 118(4): 747-786.

Dao, Mai C., Mitali Das, Zoska Koczan, and Weichang Lian. 2017. "Why is Labor Receiving a Smaller Share of Global Income? Theory and Empirical Evidence." IMF Working Paper. 
Dauth, Wolfgang, Sebastian Findeisen, Jens Südekum, and Nicole Woessner. 2017. "German Robots - The Impact of Industrial Robots on Workers." IAB Discussion Paper.

Dauth, Wolfgang, Sebastian Findeisen, Jens Suedekum, and Nicole Woessner. 2019. "The Adjustment of Labor Markets to Robots."

Eeckhout, Jan, and Philipp Kircher. 2018. "Assortative Matching With Large Firms." Econometrica, 86(1): 85-132.

Feenstra, Robert C., Robert Inklaar, and Marcel P. Timmer. 2015. "The Next Generation of the Penn World Table." American Economic Review, 105(10): 3150-3182.

Firpo, Sergio, Nicole M. Fortin, and Thomas Lemieux. 2011. "Occupational Tasks and Changes in the Wage Structure."

Ford, Martin. 2015. Rise of the Robots: Technology and the Threat of a Jobless Future. OneWorld Publications.

Frey, Carl B., and Michael A. Osbourne. 2013. "The Future of Employment: How Susceptible are Jobs to Computerization?"

Goos, Maarten, Alan Manning, and Anna Salomons. 2014. "Explaining Job Polarization: Routine-Biased Technological Change and Offshoring." American Economic Review, 104(8): 2509-2526.

Graetz, Georg, and Guy Michaels. 2015. "Robots at Work: The Impact on Productivity and Jobs."

Gregory, Terry, Anna Salomons, and Ulrich Zierahn. 2018. "Racing With or Against the Machine? Evidence from Europe." CESifo Munich Working Papers.

Griliches, Zvi. 1969. "Capital-skill complementarity." The review of Economics and Statistics, 465-468.

Grossman, Gene M., and Esteban Rossi-Hansberg. 2008. "Trading Tasks: A Simple Theory of Offshoring." American Economic Review, 98(5): 1978-1997.

Hagedorn, Marcus, Tzuo Hann Law, and Iourii Manovskii. 2017. "Identifying Equilibrium Models of Labor Market Sorting." Econometrica, 85(1): 29-65.

Hartog, Joop. 2000. "Over-education and earnings: where are we, where should we go?" Economics of Education Review, 19(2): 131 - 147.

Kantenga, Kory, and Tzou H. Law. 2016. "Sorting and Wage Inequality." Working Paper.

Koren, Miklos, Marton Csillag, and Janos Köllo. 2020. "Machines and Machinists: Incremental technical change and wage inequality." Central European University, mimeo. 
Krusell, Per, Lee E. Ohanian, José-Víctor Ríos-Rull, and Giovanni L. Violante. 2000. "Capital-skill Complementarity and Inequality: A Macroeconomic Analysis." Econometrica, 68(5): 1029-1053.

Lewandowski, Piotr, Roma Keister, Wojciech Hardy, and Szymon Górka. 2017. "Routine and Ageing? The Intergenerational Divide in the Deroutinisation of Jobs in Europe."

Lise, Jeremy, and Jean-Marc Robin. 2017. "The Macrodynamics of Sorting between Workers and Firms." American Economic Review, 107(4): 1104-1135.

Manpower Group. 2018. "Solving the Talent Shortage: Build, Buy, Borrow and Bridge."

Marimon, Ramon, and Fabrizio Zilibotti. 1999. "Unemployment vs. Mismatch of Talents: Reconsidering Unemployment Benefits." The Economic Journal, 109(455): 266-291.

Moen, Espen R. 1997. "Competitive Search Equilibrium." Journal of Political Economy, 105(2): 385-411.

Montiel, José Luis, and Carolin E. Pflueger. 2013. "A Robust Test for Weak Instruments." Journal of Business \& Economic Statistics, 31(3): 358-369.

Mortensen, Dale T., and Christopher A. Pissarides. 1994. "Job Creation and Job Destruction in the Theory of Unemployment." Review of Economic Studies, 61: 397-415.

Ottaviano, Gianmarco I. P, Giovanni Peri, and Greg C Wright. 2013. "Immigration, Offshoring, and American Jobs." American Economic Review, 103(5): 1925-1959.

Pflueger, Carolin E., and Su Wang. 2015. "A Robust Test for Weak Instruments in Stata." The Stata Journal, 15(1): 216-225.

Postel-Vinay, Fabien, and Jean-Marc Robin. 2002. "Equilibrium Wage Dispersion with Worker and Employer Heterogeneity." Econometrica, 70(6): 2295-2350.

Shimer, Robert, and Lones Smith. 2000. "Assortative Matching and Search." Econometrica, 68(2): 343-369.

Stock, James H, and Motohiro Yogo. 2002. "Testing for Weak Instruments in Linear IV Regression." National Bureau of Economic Research Working Paper 284.

Stone, P. 2016. "One Hundred Year Study on Artificial Intelligence." Stanford.

Susskind, Richard, and Daniel Susskind. 2015. The Future of the Professions. Oxford University Press.

White House. 2016. "Artifical Intelligence, Automation and the Economy." 


\section{Figures}

\section{Figure 1}

Employment and Selectivity as $A$ changes (different levels of $\Omega$ )
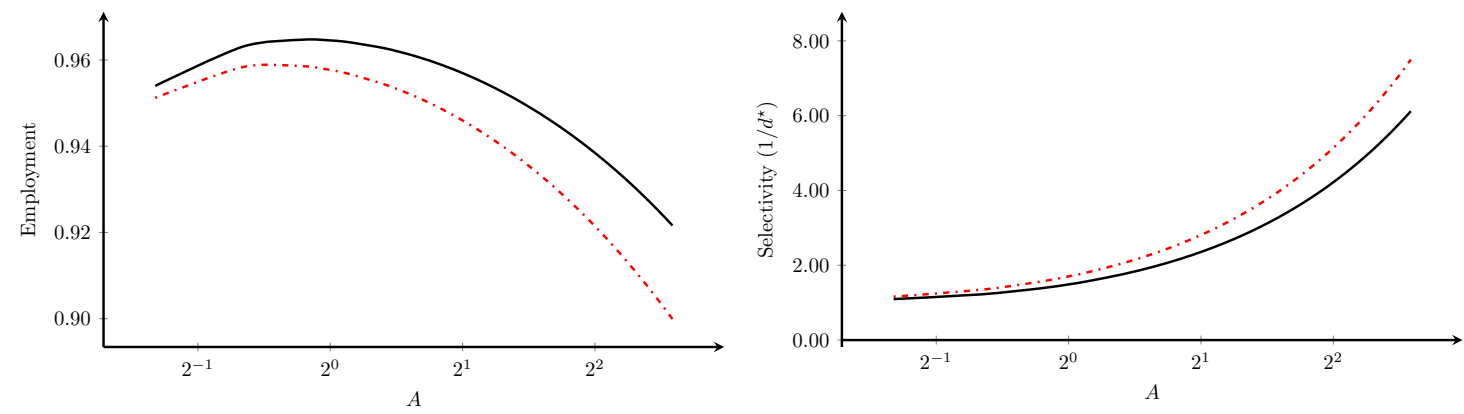

$\ldots-\Omega=0.05-\Omega=0.3$

Figure 1 plots simulated employment (left panel) and selectivity (right panel) on the y-axis over a range of automation $A$ on the x-axis for $\Omega=0.05$ (dashed red) and $\Omega=0.3$ (solid black). Values on the $\mathrm{x}$-axis are displayed on a log-scale with basis 2 . Simulations are based on the system of equations (21) - (22) and parameters as specified in Table C1.

\section{Figure 2}

Employment and Selectivity as $\Omega$ changes (different levels of $A$ )
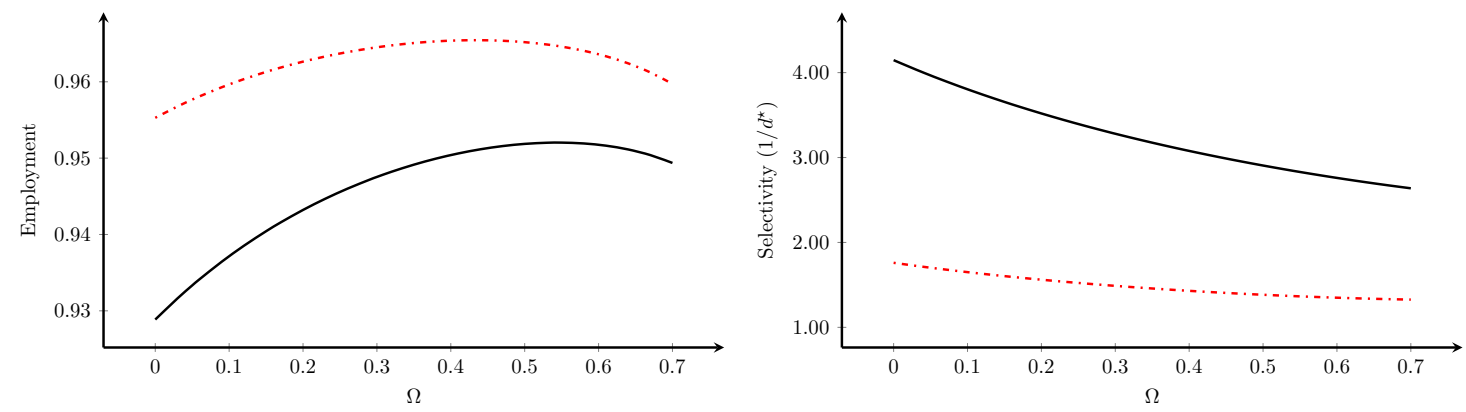

‥ $A=1-A=3$

Figure 2 plots simulated employment (left panel) and selectivity (right panel) on the y-axis over a range of offshoring $\Omega$ on the x-axis for $A=1$ (dashed red) and $A=3$ (solid black). Simulations are based on the system of equations (21) - (22) and parameters as specified in Table C1. 
Figure 3

Relative Wages of Best vs. Worst Match
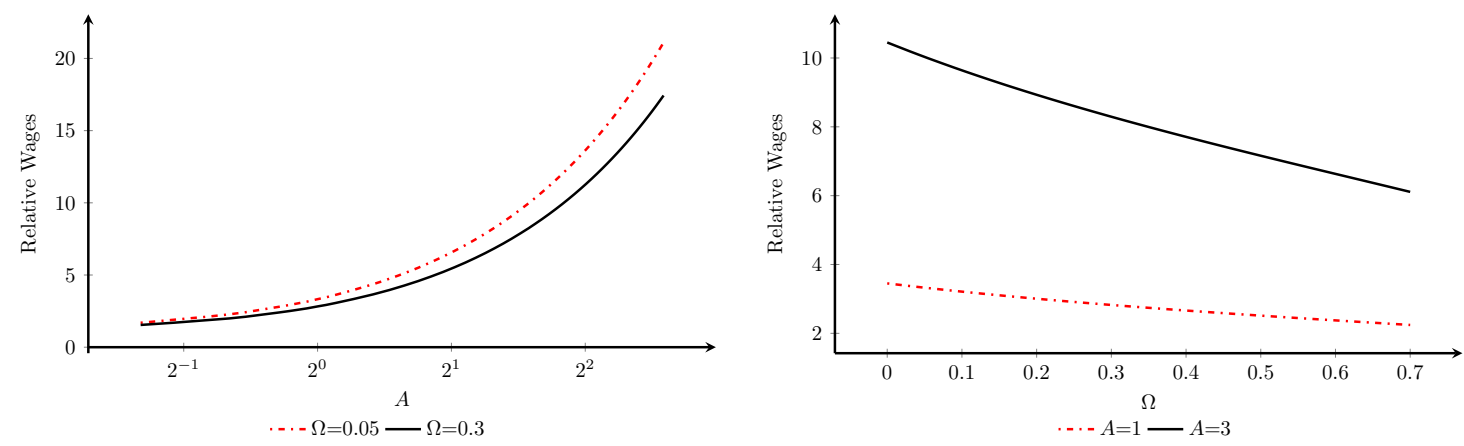

Figure 3 plots wages of the best possible match $(d=0)$ relative to the worst possible match $\left(d=d^{*}\right)$ over a range of automation $A$ on the x-axis for $\Omega=0.05$ (dashed red) and $\Omega=0.3$ (solid black) in the left panel and over a range of offshoring $\Omega$ on the x-axis for $A=1$ (dashed red) and $A=3$ (solid black) in the right panel. In the left panel values on the $\mathrm{x}$-axis are displayed on a log-scale with basis 2 . Simulations are based on the system of equations (21) - (22) with wages computed as in (23) and parameters as specified in Table C1.

Figure 4

The impact of Routineness and Offshorability on Labour Hours

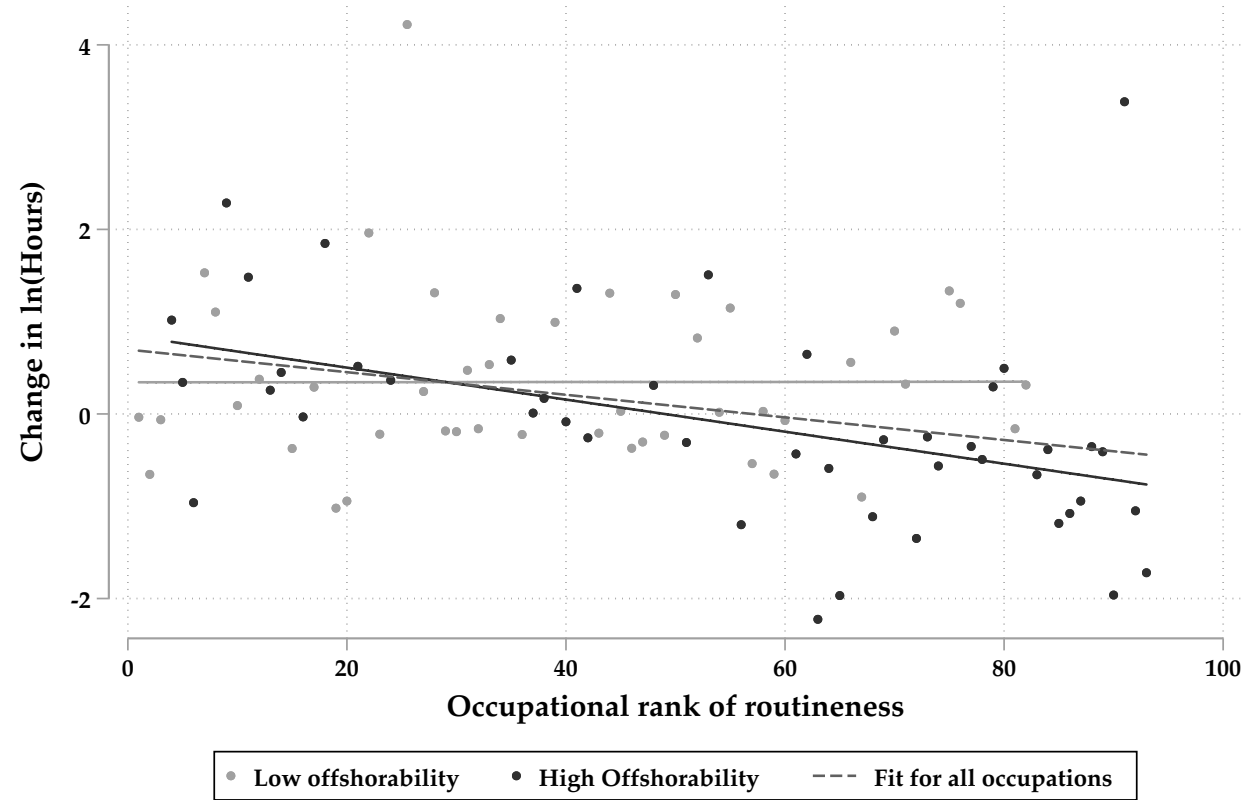

Figure 4 plots the change in hours worked from 1995 to 2010 against the occupational rank of routineness. Data on employment is aggregated at the occupation level. Routineness of the occupation is taken from Acemoglu and Autor (2011) and data on offshorability comes from Blinder and Krueger (2013). Occupations belong to the low or high offshorability sample if they are below or above the median offshorability. Occupations with below- (above-) median offshorability are displayed in grey dots (black dots) with the corresponding linear sample fit plotted as the solid grey (black) line. The overall sample fit is plotted as a dashed line. 
Figure 5

Country fixed effects and TFP change.

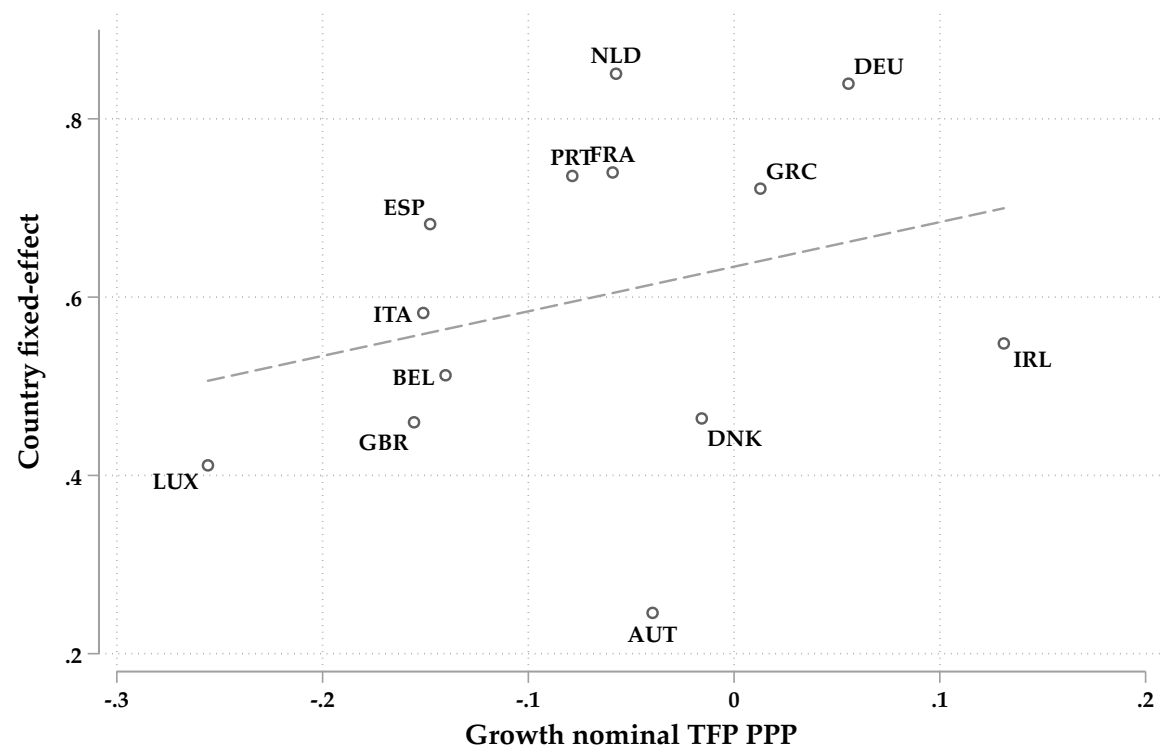

Figure 5 plots country fixed-effects $\mu_{i}$ from estimating (25) with corresponding coefficient in Table 2 column 1 against price-adjusted country-level total factor productivity. Total factor productivity comes from Penn World Tables (Feenstra, Inklaar and Timmer, 2015). The overall sample fit is plotted as a dashed grey line.

Figure 6

\section{Estimated Aggregate Effects and TFP}

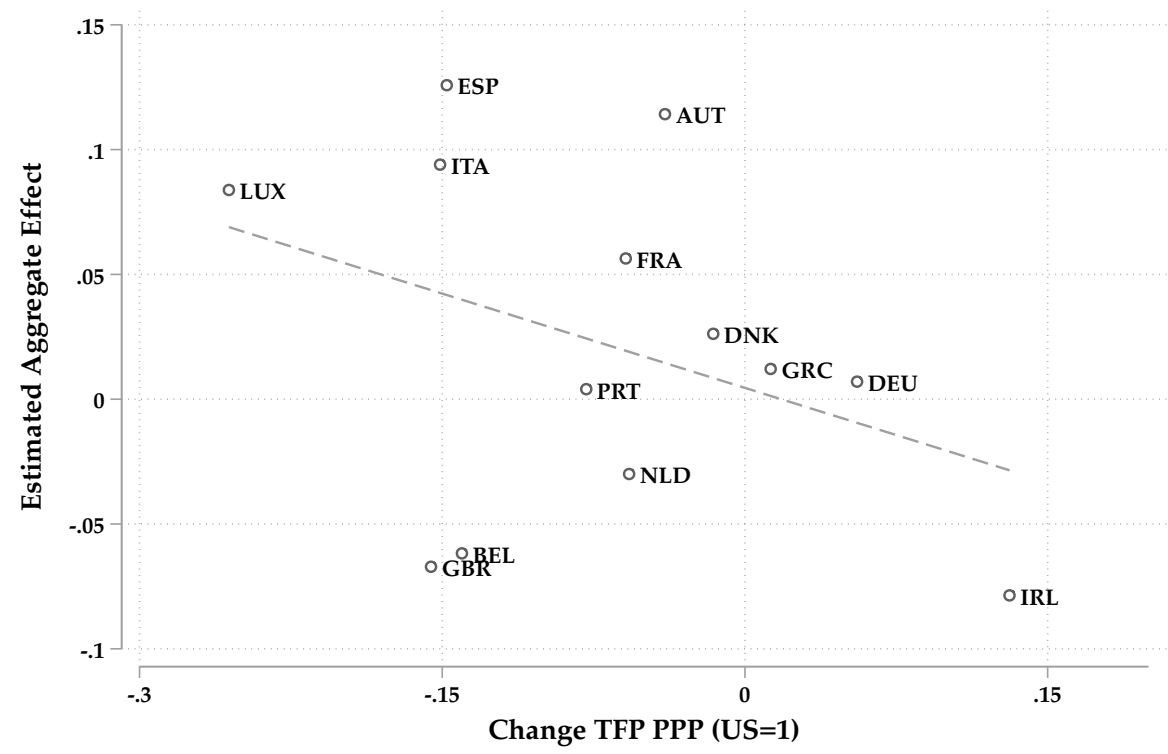

Figure 6 plots estimated aggregate effects of RTI on the change in employment from 1995 to 2010 as defined in (29) against the observed change in Total Factor Productivity. TFP comes from Penn World Tables (Feenstra, Inklaar and Timmer, 2015) and reported at constant purchasing power parity (PPP) rates relative to the US in terms of current prices. 
Tables 


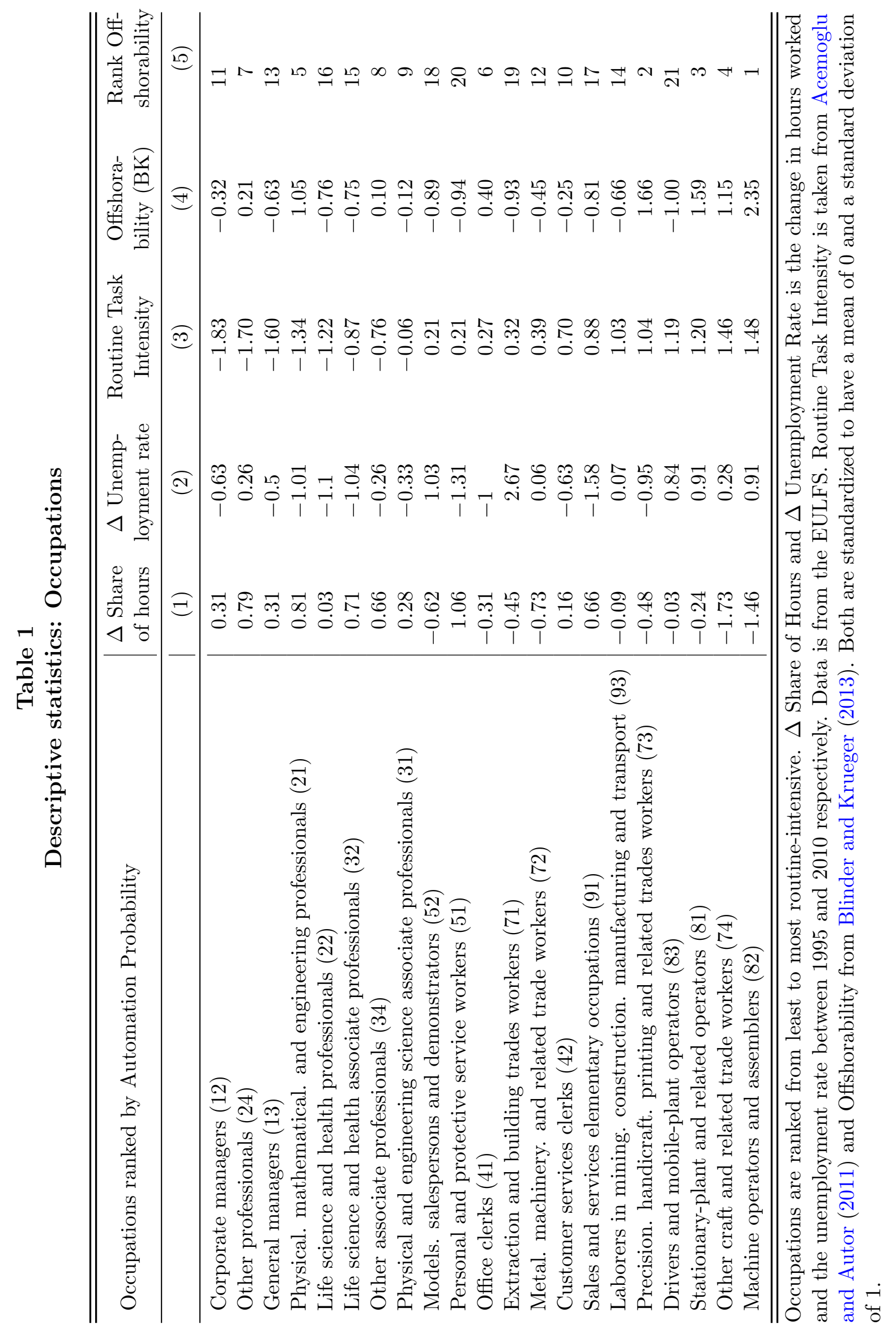


Table 2

Selectivity, Automation and Offshoring

\begin{tabular}{|c|c|c|c|c|c|}
\hline & \multicolumn{5}{|c|}{ Dep. Var.: $\Delta \ln (S S O)$} \\
\hline & (1) & $(2)$ & $(3)$ & (4) & (5) \\
\hline$R T I$ & $\begin{array}{c}0.0755 \\
(0.0522)\end{array}$ & & & $\begin{array}{c}0.0312 \\
(0.0552)\end{array}$ & \\
\hline$R T I \times I^{H}$ & & $\begin{array}{c}0.207^{* *} \\
(0.100)\end{array}$ & $\begin{array}{c}0.168^{*} \\
(0.0994)\end{array}$ & & $\begin{array}{c}0.301^{* *} \\
(0.150)\end{array}$ \\
\hline$R T I \times I^{L}$ & & $\begin{array}{l}-0.0151 \\
(0.0792)\end{array}$ & $\begin{array}{l}0.00885 \\
(0.0781)\end{array}$ & & $\begin{array}{l}0.00952 \\
(0.0972)\end{array}$ \\
\hline Offshor. & $\begin{array}{l}-0.0765^{*} \\
(0.0414)\end{array}$ & $\begin{array}{c}-0.0923^{* *} \\
(0.0432)\end{array}$ & $\begin{array}{l}-0.123^{* *} \\
(0.0525)\end{array}$ & $\begin{array}{l}-0.0691 \\
(0.0427)\end{array}$ & $\begin{array}{c}-0.0943^{* *} \\
(0.0440)\end{array}$ \\
\hline$R T I \times O f f s h o r$ & & & $\begin{array}{c}0.0667 \\
(0.0470)\end{array}$ & & \\
\hline Share ${ }^{95}$ & & & & $\begin{array}{l}0.0727 \\
(2.117)\end{array}$ & \\
\hline Share $^{95} \times R T I$ & & & & $\begin{array}{c}4.874^{* * *} \\
(1.596)\end{array}$ & \\
\hline$S S O^{95}$ & $\begin{array}{c}-1.146^{* * *} \\
(0.184)\end{array}$ & $\begin{array}{c}-1.231^{* * *} \\
(0.189)\end{array}$ & $\begin{array}{c}-1.328^{* * *} \\
(0.203)\end{array}$ & $\begin{array}{c}-1.156^{* * *} \\
(0.183)\end{array}$ & $\begin{array}{c}-1.268^{* * *} * \\
(0.195)\end{array}$ \\
\hline Observations & 1,063 & 1,063 & 1,063 & 1,063 & 1,063 \\
\hline R-squared & 0.139 & 0.143 & 0.149 & 0.146 & 0.115 \\
\hline $\begin{array}{l}\text { Fixed effects } \\
\text { Spillover Controls }\end{array}$ & Country & Country & Country & Country & $\begin{array}{c}\text { Country } \\
\text { Yes }\end{array}$ \\
\hline
\end{tabular}

The table reports coefficients of estimating (25) in column 1 and 4 and (26) in column 2,3 and 5. The dependent variable is the change of the Sectoral Selectivity of an Occupation (SSO) calculated as the Herfindahl index of occupational employment shares across industries in a country. $R T I$ is routine-task intensity as in Acemoglu and Autor (2011). $I^{H}$ is a dummy variable that takes value one if the occupation's RTI is above the median RTI across all occupations in a country and zero otherwise; $I^{L}$ is defined as $1-I^{H}$. Offshor. measures the offshorability of an occupation as in Blinder and Krueger (2013). Share ${ }^{95}$ is the employment share of a given occupation and $S S O^{95}$ is the sectoral selectivity, both measured in 1995. Column 5 includes the interaction of $I^{H}$ with its respective average at the country-level, excluding the occupation considered, to control for spillovers as suggested by Berg and Streitz (2019). Data is aggregated at the country $\times$ occupation level. Robust standard errors clustered at the occupation level in parentheses. ${ }^{* * *} \mathrm{p}<0.01,{ }^{* *} \mathrm{p}<0.05$, * $\mathrm{p}<0.1$. 
Table 3

Selectivity and Employment I

\begin{tabular}{|c|c|c|c|c|c|}
\hline & \multicolumn{5}{|c|}{ Dep. Var.: $\Delta \ln ($ Hours $)$} \\
\hline & (1) & (2) & (3) & (4) & (5) \\
\hline$\Delta \ln (S S O)$ & $\begin{array}{c}-0.160^{* * *} \\
(0.0417)\end{array}$ & $\begin{array}{l}-0.161^{*} \\
(0.0852)\end{array}$ & $\begin{array}{c}-0.169^{* * *} \\
(0.0349)\end{array}$ & $\begin{array}{c}-0.267^{* * *} \\
(0.0658)\end{array}$ & $\begin{array}{c}-0.446^{* * *} \\
(0.0809)\end{array}$ \\
\hline$\Delta \ln \left(L^{b}\right)$ & $\begin{array}{c}0.266^{* * *} \\
(0.0640)\end{array}$ & $\begin{array}{l}0.266^{* * *} \\
(0.0647)\end{array}$ & $\begin{array}{l}0.297^{* * *} \\
(0.0629)\end{array}$ & $\begin{array}{l}0.302^{* * *} \\
(0.0650)\end{array}$ & $\begin{array}{c}0.0697 \\
(0.0883)\end{array}$ \\
\hline$R T I$ & & & $\begin{array}{c}-0.226^{* * * *} \\
(0.0425)\end{array}$ & $\begin{array}{c}-0.225^{* * *} \\
(0.0427)\end{array}$ & \\
\hline Offshor. & & & $\begin{array}{c}0.0719 \\
(0.0562)\end{array}$ & $\begin{array}{c}0.0668 \\
(0.0578)\end{array}$ & \\
\hline$R T I \times$ Offshor & & & $\begin{array}{c}-0.178^{* * *} \\
(0.0447)\end{array}$ & $\begin{array}{c}-0.181^{* * *} \\
(0.0453)\end{array}$ & \\
\hline First Stage & & $\begin{array}{c}1.780^{* * *} \\
(0.127)\end{array}$ & & $\begin{array}{c}1.789 * * * \\
(0.139)\end{array}$ & $\begin{array}{c}1.925^{* * *} \\
(0.204)\end{array}$ \\
\hline $\begin{array}{l}\text { FE } \\
\text { Instrument }\end{array}$ & $\begin{array}{l}\text { Country } \\
\text { No }\end{array}$ & $\begin{array}{l}\text { Country } \\
\text { Bartik }\end{array}$ & $\begin{array}{l}\text { Country } \\
\text { No }\end{array}$ & $\begin{array}{l}\text { Country } \\
\text { Bartik }\end{array}$ & $\begin{array}{c}\text { Country } \times \text { Occup } \\
\text { Bartik }\end{array}$ \\
\hline $\begin{array}{l}\text { Observations } \\
\text { K-P F-Test 1st }\end{array}$ & 1,073 & $\begin{array}{l}1,073 \\
196.6\end{array}$ & 1,062 & $\begin{array}{l}1,062 \\
165.1\end{array}$ & $\begin{array}{l}1,073 \\
88.71\end{array}$ \\
\hline
\end{tabular}

The table reports coefficients of estimating (28). The dependent variable is the log change in hours worked between 1995 and 2010. $\Delta \ln (S S O)$ is the log change of the Sectoral Selectivity of an Occupation calculated as the Herfindahl index of occupational employment shares across industries in a country. $\Delta \ln \left(L^{b}\right)$ is the predicted employment growth rate calculated from the growth rate in all other countries. In Column 2,4 and 5 we instrument $\Delta \ln (S S O)$ using the double-Bartik instrument constructed from Bartik-predicted employment shares. Corresponding first-stage estimates on the included instruments are displayed below the second-stage coefficients. RTI is routine-task intensity as in Acemoglu and Autor (2011) and Offshor. measures the offshorability of an occupation as in Blinder and Krueger (2013). Data is aggregated at the country $\times$ occupation level. Standard errors in parentheses are clustered at the occupation level in parentheses. ${ }^{* * *} \mathrm{p}<0.01,{ }^{* *} \mathrm{p}<0.05,{ }^{*}$ $\mathrm{p}<0.1$. 
Table 4

Selectivity and Employment II

\begin{tabular}{|c|c|c|c|c|c|c|}
\hline & \multicolumn{5}{|c|}{ Dep. Var.: $\Delta \ln ($ Hours $)$} & \multirow[b]{2}{*}{ (6) } \\
\hline & (1) & (2) & (3) & (4) & (5) & \\
\hline$\Delta \ln (S S O)$ & $\begin{array}{c}-0.339 * * * \\
(0.101)\end{array}$ & $\begin{array}{c}-0.694^{* * *} \\
(0.151)\end{array}$ & & & & \\
\hline$\Delta \ln (S S O) \times I^{H}$ & & & $\begin{array}{c}-0.343^{* * *} \\
(0.119)\end{array}$ & $\begin{array}{c}-0.507^{* * *} \\
(0.159)\end{array}$ & $\begin{array}{c}-0.357^{* * *} \\
(0.126)\end{array}$ & $\begin{array}{c}-0.714^{* *} \\
(0.288)\end{array}$ \\
\hline$\Delta \ln (S S O) \times I^{L}$ & & & $\begin{array}{c}0.105 \\
(0.107)\end{array}$ & $\begin{array}{l}0.0594 \\
(0.112)\end{array}$ & $\begin{array}{l}0.244^{* *} \\
(0.0973)\end{array}$ & $\begin{array}{c}0.241^{* *} \\
(0.109)\end{array}$ \\
\hline$\Delta \ln \left(L^{b}\right)$ & $\begin{array}{c}0.223^{* * *} \\
(0.0845)\end{array}$ & $\begin{array}{l}-0.145 \\
(0.109)\end{array}$ & $\begin{array}{l}0.326^{* * *} \\
(0.0700)\end{array}$ & $\begin{array}{l}0.248^{* * *} \\
(0.0764)\end{array}$ & $\begin{array}{c}0.113 \\
(0.0846)\end{array}$ & $\begin{array}{r}-0.0954 \\
(0.116)\end{array}$ \\
\hline$R T I$ & $\begin{array}{c}-0.194^{* * *} \\
(0.0511)\end{array}$ & & & & & \\
\hline Offshor. & $\begin{array}{c}0.0445 \\
(0.0644)\end{array}$ & & $\begin{array}{l}0.00564 \\
(0.0521)\end{array}$ & $\begin{array}{c}0.0340 \\
(0.0606)\end{array}$ & & \\
\hline$R T I \times O f f$ shor & $\begin{array}{c}-0.182^{* * *} \\
(0.0507)\end{array}$ & & $\begin{array}{c}-0.205^{* * *} \\
(0.0394)\end{array}$ & $\begin{array}{c}-0.147^{* * *} \\
(0.0485)\end{array}$ & & \\
\hline $\begin{array}{l}\mathrm{FE} \\
\text { Instrument } \\
\Delta \ln (S S O)>0\end{array}$ & $\begin{array}{c}\text { Bartik } \\
\text { Yes }\end{array}$ & $\begin{array}{c}\text { Occup. } \\
\text { Bartik } \\
\text { Yes }\end{array}$ & Bartik & $\begin{array}{l}\text { Bartik } \\
\text { Yes }\end{array}$ & $\begin{array}{l}\text { Occup. } \\
\text { Bartik }\end{array}$ & $\begin{array}{c}\text { Occup. } \\
\text { Bartik } \\
\text { Yes }\end{array}$ \\
\hline Observations & 558 & 563 & 1,062 & 558 & 1,073 & 563 \\
\hline K-P F-Test 1st & 90.11 & 63.88 & 24.31 & 17.93 & 9.593 & 11 \\
\hline
\end{tabular}

The table reports coefficients of estimating (28). The dependent variable is the change in hours worked between 1995 and 2010. $\Delta \ln (S S O)$ is the log change of the Sectoral Selectivity of an Occupation calculated as the Herfindahl index of occupational employment shares across industries in a country. $\Delta \ln \left(L^{b}\right)$ is the predicted employment growth rate calculated from the growth rate in all other countries. In Column 2,4 and 5 we instrument $\Delta \ln (S S O)$ using the double-Bartik instrument constructed from predicted employment shares. Corresponding first-stage estimates on the included instruments are displayed below second-stage coefficients. RTI is routine-task intensity as in Acemoglu and Autor (2011). $I^{H}$ is a dummy variable that takes value one if the occupation's $R T I$ is above the median $R T I$ across all occupations in a country and zero otherwise; $I^{L}$ is defined as $1-I^{H}$. Offshor. measures the offshorability of an occupation as in Blinder and Krueger (2013). Data is aggregated at the country $\times$ occupation level. Standard errors in parentheses are clustered at the occupation level in parentheses. ${ }^{* *} \mathrm{p}<0.01,{ }^{* *} \mathrm{p}<0.05,{ }^{*} \mathrm{p}<0.1$. 
Table 5

Impact of Technology on Educational Mismatch and Unemployment Duration

\begin{tabular}{lcccc}
\hline \hline & $\begin{array}{c}\Delta \text { Unemployment } \\
\text { Duration }\end{array}$ & $\Delta$ Mismatch & $\begin{array}{c}\Delta \text { Under } \\
\text { Education }\end{array}$ & $\begin{array}{c}\Delta \text { Over } \\
\text { Education }\end{array}$ \\
\cline { 2 - 5 } & $(1)$ & $(2)$ & $(3)$ & $(4)$ \\
\hline$R T I$ & $0.0409^{*}$ & -0.0347 & $-0.00340^{* * *}$ & $0.00305^{* * *}$ \\
Offshor. & $(0.0243)$ & $(0.0984)$ & $(0.000742)$ & $(0.000778)$ \\
RTI $\times$ Offshor. & -0.0183 & 0.0532 & $0.00220^{* *}$ & $-0.00167^{* *}$ \\
& $(0.0319)$ & $(0.114)$ & $(0.000858)$ & $(0.000795)$ \\
\hline Observations & 0.0454 & $-0.290^{* * *}$ & $-0.00177^{* *}$ & -0.00113 \\
R-squared & $(0.0328)$ & $(0.111)$ & $(0.000814)$ & $(0.000805)$ \\
Fixed effects & 905 & 1,915 & 1,915 & 1,915 \\
\hline \hline
\end{tabular}

$\Delta$ Over- (Under-) Education is defined as the change from 1995 to 2010 in the proportion of workers having more (less) years of education exceeding the 10-year occupation $\times$ industry $\times$ country average by more than 2 standard deviations. $\Delta$ Mismatch is the change from 1995 to 2010 in the proportion of workers either under- or over-educated. Occupations are aggregated to the 2-digit ISCO88 level. Unemployment duration is computed based on the cell of the worker's last job. Regressions are weighted by initial employment shares and all right-hand side variables are standardized so their mean equals zero and their standard deviation equals one. Standards errors in parentheses are clustered at the occupation $\times$ country level. ${ }^{* * *} \mathrm{p}<0.01,{ }^{* *} \mathrm{p}<0.05,{ }^{*} \mathrm{p}<0.1$. 


\section{A Data Description}

We use the annual files of the European Labour Force Survey (EULFS) made available by Eurostat. This survey combines labour force surveys conducted at the national level in European countries. It has the advantage to provide harmonized information on basic labour markets variables. Our final database corresponds to country $\times$ industry $\times$ occupation $\times$ year cells. The information on the sector is based on the broad NACE sectors $(21$ sectors in the NACE Rev.2 classification) and the information on the occupation is based on the 3digits ISCO-88 classification. The EULFS is used to derive the number of employed and unemployed workers in each cell by collapsing individuals observations using the provided weighting coefficients. We also use the EULFS to compute the unemployment duration in each cell.

Construction of the variables We keep the employed people as defined by the ILO criteria and derived by Eurostat. It is less common to compute unemployment at the sector $\times$ occupation level since workers can be mobile across sectors and occupations. We define unemployment in a given sector and a given occupation as the number of unemployed people who had this precise occupation in this precise sector. This measure corresponds to the true and unobservable unemployment rate at the sector $\times$ occupation level if workers do not move across sectors and occupations.

Dataset selection We restrict our dataset to the 13 following countries: Austria, Belgium, Germany, Denmark, Spain, France, United Kingdom, Greece, Ireland, Italy, Luxembourg, Netherlands and Portugal. This group of countries corresponds to all countries that provided data at least from 1995. It is important to note that France and the Netherlands do not provide enough information to compute the unemployment rate at the cell level. Following Goos, Manning and Salomons (2014), we also drop the following industries: Agriculture, Forestry, Fishing (A); Mining and Quarrying (B), Public Administration and Defence and Compulsory Social security $(\mathrm{O})$; Education $(\mathrm{P})$ and Extra-territorial organizations and bodies (U). These sectors corresponds to public sectors and agricultural sectors. They account for $26 \%$ of all jobs in our sample. The following occupations, closely associated to the sectors deleted are also dropped from the sample: Legislators and senior officials (ISCO-88: 11); teaching professionals (ISCO-88: 23); teaching associate professionals (ISCO-88: 33); market-oriented skilled agricultural and fishery workers (ISCO-88: 61); agricultural, fishery and related labourers (ISCO-88: 92). ${ }^{36}$ Finally, our data contains information, virtually complete, at the cell level for 92 occupations, in 16 sectors.

\footnotetext{
${ }^{36}$ These occupations respectively account for $0.12 \%, 0.27 \%, 0.53 \%, 0.39 \%$ and $0.07 \%$ observations in the sectors kept.
} 
Table A1 sums up the coverage of our database relative to official statistics. According to official Eurostat statistics, we cover around $70 \%$ of the employment in each country, except for Luxembourg for which we only cover $58.5 \%$ of the employment. This is due to the fact that Luxembourg is a small country with a large institutional sector driven by the presence of some European institutions. Our coverage of unemployment is a bit less precise, going from $36.2 \%$ of official unemployment numbers in Italy to $69.6 \%$ in Denmark. This is principally due to the lack of precise reporting of the last job for unemployed people and to dropped industries. Especially the coverage is very low for Portugal in 1995 (around 10\%).

\section{Table A1 \\ Database Coverage (in \% of official Eurostat figures)}

\begin{tabular}{ccc}
\hline Country & \# of employees & $\begin{array}{c}\# \\
\text { ployed workers }\end{array}$ \\
\hline Austria & $70,9 \%$ & $56,1 \%$ \\
Belgium & $70,5 \%$ & $51,5 \%$ \\
Germany & $75,4 \%$ & $62,3 \%$ \\
Denmark & $73,3 \%$ & $69,6 \%$ \\
Spain & $70,5 \%$ & $61,1 \%$ \\
France & $69,1 \%$ & - \\
United Kingdom & $74,2 \%$ & $59,8 \%$ \\
Greece & $61,1 \%$ & $42,3 \%$ \\
Ireland & $66,5 \%$ & $51,1 \%$ \\
Italy & $71,8 \%$ & $36,2 \%$ \\
Luxembourg & $58,5 \%$ & $44,0 \%$ \\
Netherlands & $68,0 \%$ & - \\
Portugal & $69,8 \%$ & $38,6 \%$ \\
\hline
\end{tabular}

The time frame of our analysis corresponds to 1995-2010 in order to include the maximum number of countries. Our analysis stops in 2010 because after this date, a change in the occupation classification (ISCO-88 to ISCO-08) prevents us from accurately representing changes in the time series.

\section{A.1 Offshorability}

Three different measures of offshorability are proposed in the literature: by Blinder (2009), by Blinder and Krueger (2013, hereafter BK) and by Acemoglu and Autor (2011, hereafter AA). In the first two cases, the authors propose a qualitative scale of offshorability, ranking occupations from "Highly Non Offshorable" (1) to "Highly Offshorable" (4) (Blinder, 2009). Blinder then proposes a qualitative ranking of occupations according to their de- 
Table A2

Correlation table between offshorability measures

\begin{tabular}{l|ccc} 
& AA (2011) & Blinder (2009) & BK (2013) \\
\hline Acemoglu-Autor (2011) & 1 & - & \\
Blinder (2009) & 0.34 & 1 & - \\
Blinder-Krueger (2013) & 0.25 & 0.94 & 1
\end{tabular}

gree of offshorability. BK only provide 4 categories. AA propose a quantitative index of offshorability based on ONET. ${ }^{37}$ Their measure aggregates several ONET indicators: Face to face discussions, Assisting and Caring for Others, Performing for or Working Directly with the Public, Inspecting Equipment, Structures, or Material, Handling and Moving Objects, $0.5 *$ Repairing and Maintaining Mechanical Equipment, $0.5 *$ Repairing and Maintaining Electronic Equipment.

While Blinder and BK measures are based on questionnaires and qualitative observations about offshorability, the AA measure is not. The two types of measures are likely to diverge for some occupations. In Table A2, we compute the correlation coefficient between these measures. The correlation between Blinder and BK indexes is large while for both indices the correlation with the AA measure is quite low.

For instance, Models, Salespersons and Demonstrators (code 52) is an occupation classified among the five most offshorable occupations according to the AA index while it is ranked as Highly Non-Offshorable by Blinder (2009). Teaching professionals (code 23) are also in the same situation. On the contrary, Machine operators and assemblers (code 82) are ranked as offshorable in Blinder (2009) while being ranked as a low offshorability activity by the AA index.

In their data appendix Goos, Manning and Salomons (2014) compare different offshorability index with actual offshorability measures. Blinder/BK types of measures seem more reliable. We consider these two measures as our preferred ones, using the BK index in our baseline regressions.

\section{A.2 Automation}

We proxy the probability of future automation of an occupation using the RTI measure constructed by Autor and Dorn (2009). This measure correlates with the one provided by Frey and Osbourne (2013). Using the files by Acemoglu and Autor (2011) and the definition of the RTI by Lewandowski et al. (2017) we compute the RTI index based on

\footnotetext{
${ }^{37}$ This index is inspired by Firpo, Fortin and Lemieux (2011)
} 


\section{Figure A1}

\section{Correlation between automation probability and routineness}

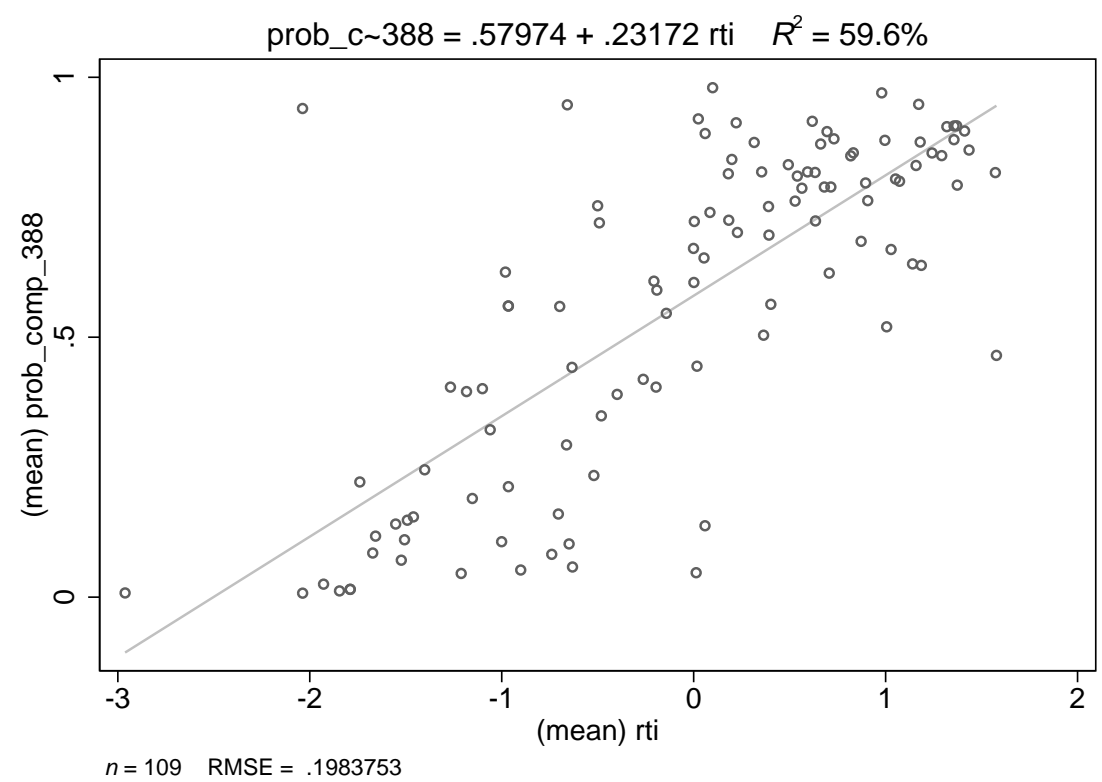

DOT data. ${ }^{38}$ The measure of the RTI is standardized in order to have a mean of zero and a standard error of one. We use a crosswalk to go from SOC 2000 classification to 4-digits ISCO88 classification and then aggregate it to the three-digits ISCO88 classification. At this level the correlation between the RTI ('routineness') and measure by Frey and Osborne ('probability of automation') is 0.77 (see figure A1). However, the two variables diverge for some occupations.

To assess the evolution of routine jobs across countries and industries, Dao et al. (2017) also use an index of 'routineness' fixed for the nine 1-digit ISCO-88 occupations. They then assume that the partition of jobs within 1-digit ISCO occupations is fixed among countries, industries and time. We relax this assumption by only assuming that the RTI of a 3-digits ISCO occupation is fixed. This way we are able to observe the evolution in the automatability by country, industry and occupation.

\section{A.3 Link between automation probability and offshorability}

In this subsection we document that automatability and offshorability are not trivially correlated. First, conceptually the two concepts are different. Offshorability is defined as "the ability to perform one's work duties (for the same employer and customers) in a foreign

\footnotetext{
${ }^{38}$ Lewandowski et al. (2017) slightly modify the RTI definition compared to Autor and Dorn (2009) in order to adapt it to the use of ONET data instead of DOT data: RTI $=\ln ($ RoutineCognitive+RoutineManual $)-$ $\ln ($ Nonroutineanalytical + nonroutineinterpersonnal $)$.
} 
Figure A2

Automation probability and Offshorability (BK, 09)

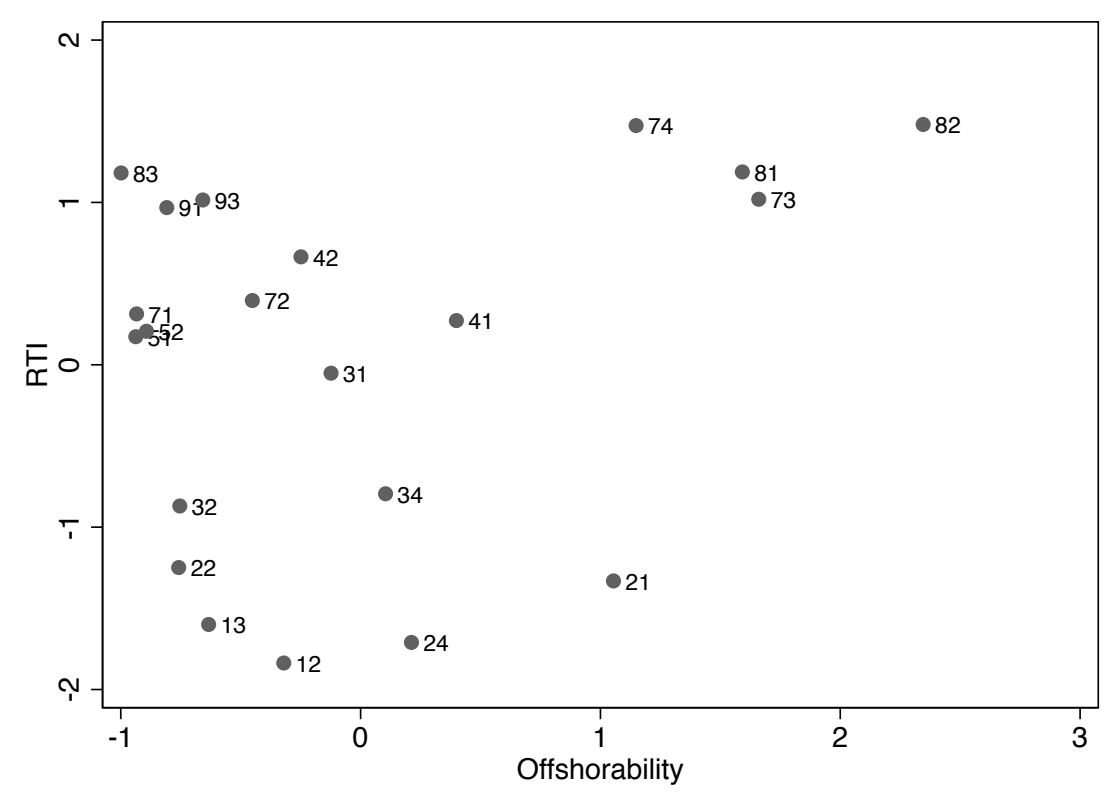

country but still supply the good or service to the home market" (Blinder and Krueger, 2009) while the automatability is more strictly linked to the routineness of a task, its possibility to be solved algorithmically, etc. Figure A2 documents the correlation between the two variables. There is a global positive correlation but the figure also highlights the diversity of RTI/offshorability combinations. Especially some occupations are both offshorable and routine-intensive (73: Precision, handicraft, printing and related trades workers; 81: Stationary-plant and related operators; 82: machine operators and assemblers), other are not routine intensive but offshorable (21: Physical, mathematical and engineering science professional) while some are protected from offshorability but at risk of automation (83: Drivers and mobile-plant operators; 91: sales and services elementary occupations; 93: labourers in mining, construction, manufacturing and transport). Finally, some occupations are both protected from automation and from offshorability (12: corporate managers; 13: general managers; 22: life science and health professionals). Note, however, that the scope of occupations that are not routine intensive but offshorable is very limited.

\section{A.4 Merging procedure}

Our matching strategy could be decomposed as follows: i) We only keep the observations before 2011, ii) we compute the RTI for each 4-digit ISCO-88 using official crosswalks, iii) we average the probabilities of automation when many SOC occupations are matched into 
a single ISCO occupation, iv) we take the unweighted average probability of automation to aggregate our measure at the 3-digits ISCO-88 levels, v) we match each occupation with its RTI, vi) we proceed in the same way to assign RTI and offshorability indexes to occupation reported at the 2-digits ISCO level. Finally, when necessary, we obtain the measure of routine task intensity and offshorability at the 2-digits ISCO level by collapsing (with appropriate weights) all observations at the 3 -digits level in their corresponding 2-digits ISCO occupation.

\section{B Model Solution}

This Appendix provides a detailed derivation of (21), (22) and (23) in the main text. The steady state equilibrium is characterized by the following equations:

- Surplus function:

$$
s(d)=\frac{\Phi}{2} A^{\frac{1}{1-\beta}}(1-\Omega)[F(1+\Omega)-\gamma A d] .
$$

- Matching function:

$$
M(U, V)=\vartheta U^{\xi} V^{1-\xi}
$$

- Resource constraint:

$$
E+U=L=1 .
$$

- Flow condition:

$$
2 d^{*} M(U, V)=\delta E .
$$

- Meeting probabilities:

$$
\begin{gathered}
q_{v}=M(U, V) / V=\vartheta(U / V)^{\xi} . \\
q_{u}=M(U, V) / U=\vartheta(V / U)^{1-\xi} .
\end{gathered}
$$

- Optimality conditions:

$$
\begin{gathered}
\rho v_{E}(d)=w(d)-\delta\left(v_{E}(d)-v_{U}\right), \\
\rho v_{P}(d)=(s(d)-w(d)-c)-\delta\left(v_{P}(d)-v_{v}\right), \\
\rho v_{U}=2 q_{u} \int_{0}^{d^{*}}\left(v_{E}(z)-v_{U}\right) d z \\
\rho v_{V}=-c+2 q_{v} \int_{0}^{d^{*}}\left(v_{P}(z)-v_{V}\right) d z .
\end{gathered}
$$


- Bargaining outcome:

$$
(1-\alpha)\left(v_{E}(d)-v_{U}\right)=\alpha\left(v_{P}(d)-v_{V}\right)
$$

- Free entry condition:

$$
v_{V}=0 .
$$

- Zero cutoff value condition:

$$
v_{P}\left(d^{*}\right)=0
$$

From this system of 13 equations in 13 unknowns $\left(E, U, V, M, q_{v}, q_{u}, w, v_{E}, v_{p}, v_{U}, v_{V}\right.$, $\left.s, d^{*}\right),(21)$ and (22) can be obtained as follows. Subtract (38) from (36) to obtain:

$$
\int_{0}^{d^{*}}\left(v_{E}(z)-v_{u}\right) d z=\frac{\int_{0}^{d^{*}} w(z) d z}{\rho+\delta+2 q_{u}(\theta)}
$$

Subtract (39) from (37) to obtain:

$$
\int_{0}^{d^{*}}\left(v_{P}(z)-v_{V}\right) d z=\frac{\int_{0}^{d^{*}}(s(z)-w(z)) d z}{\rho+\delta+2 q_{v}(\theta)} .
$$

Substitute into the integral of (40)

$$
(1-\alpha) \int_{0}^{d^{*}}\left(v_{E}(z)-v_{U}\right) d z=\alpha \int_{0}^{d^{*}}\left(v_{P}(z)-v_{V}\right) d z
$$

to obtain:

$$
w(z)=\frac{\alpha\left(\delta+\rho+2 q_{u}(\theta)\right) s(z)}{\delta+\rho+(1-\alpha) 2 q_{v}(\theta)+\alpha 2 q_{u}(\theta)} .
$$

Substitute (40) into (39) to obtain:

$$
\rho v_{V}==-c+2 q_{v}(\theta) \frac{1-\alpha}{\alpha} \int_{0}^{d^{*}}\left(v_{E}(z)-v_{U}\right) d z .
$$

Substitute (46) into (43) to obtain:

$$
\int_{0}^{d^{*}}\left(v_{E}(z)-v_{u}\right) d z==\frac{\alpha \int_{0}^{d^{*}} s(z) d z}{\delta+\rho+(1-\alpha) 2 q_{v}(\theta)+\alpha 2 q_{u}(\theta)}
$$

Hence (47) and (48) imply:

$$
\rho v_{V}=-c+\frac{(1-\alpha) 2 q_{v}(\theta) \int_{0}^{d^{*}} s(z) d z}{\delta+\rho+(1-\alpha) 2 q_{v}(\theta)+\alpha 2 q_{u}(\theta)}
$$


Using (33) and (32) in (35) gives:

$$
q_{u}=\frac{M(U, V)}{U}=\frac{\delta E}{2 d^{*}(L-E)} .
$$

Using (33) and (32) gives

$$
V=\left(\frac{\delta E}{2 d^{*} \vartheta U^{\xi}}\right)^{\frac{1}{1-\xi}}
$$

which, once substituted into (34), gives:

$$
q_{v}=\vartheta^{\frac{1}{1-\xi}}(\delta E)^{-\frac{\xi}{1-\xi}}(L-E)^{\frac{\xi}{1-\xi}}\left(2 d^{*}\right)^{\frac{\xi}{1-\xi}}
$$

or equivalently

$$
q_{v}=\vartheta^{\frac{1}{1-\xi}}\left(q_{u}\right)^{-\frac{\xi}{1-\xi}}
$$

Substituting (52) into (46) gives (23) in the main text:

$$
w(d)=\frac{\alpha\left(\delta+\rho+2 q_{u}\right)}{\delta+\rho+2(1-\alpha) \vartheta^{\frac{1}{1-\xi}}\left(q_{u}\right)^{-\frac{\xi}{1-\xi}}+2 \alpha q_{u}} s(d) .
$$

Now substitute (52) into (49) to obtain:

$$
\rho v_{V}=-c+\frac{2(1-\alpha) \vartheta^{\frac{1}{1-\xi}}\left(q_{u}\right)^{-\frac{\xi}{1-\xi}} \int_{0}^{d^{*}} s(z) d z}{\delta+\rho+2(1-\alpha) \vartheta^{\frac{1}{1-\xi}}\left(q_{u}\right)^{-\frac{\xi}{1-\xi}}+2 \alpha q_{u}}
$$

Hence, by (18), (53) becomes:

$$
\frac{2(1-\alpha) \vartheta^{\frac{1}{1-\xi}}\left(q_{u}\right)^{-\frac{\xi}{1-\xi}} \int_{0}^{d^{*}} s(z) d z}{\delta+\rho+2(1-\alpha) \vartheta^{\frac{1}{1-\xi}}\left(q_{u}\right)^{-\frac{\xi}{1-\xi}}+2 \alpha q_{u}}=c,
$$

which is (21) in the main text where (30) implies:

$$
\int_{0}^{d^{*}} s(z) d z=\frac{\Phi}{4} A^{\frac{1}{1-\beta}}(1-\Omega) d^{*}\left[2 F(1+\Omega)-\gamma A d^{*}\right] .
$$

Finally, substitute (18) and (42) into (37) to obtain

$$
w(d *)=s(d *)-c,
$$


which, together with (B) evaluated at $d^{*}$

$$
w\left(d^{*}\right)=\frac{\alpha\left(\delta+\rho+2 q_{u}\right) s\left(d^{*}\right)}{\delta+\rho+2(1-\alpha) q_{v}+2 \alpha q_{u}},
$$

gives:

$$
(1-\alpha) \frac{\delta+\rho+2 q_{v}}{\delta+\rho+2(1-\alpha) q_{v}+2 \alpha q_{u}} s\left(d^{*}\right)=c .
$$

Substituting (52) gives:

$$
(1-\alpha) \frac{\delta+\rho+2 \vartheta^{\frac{1}{1-\xi}}\left(q_{u}\right)^{-\frac{\xi}{1-\xi}}}{\delta+\rho+2(1-\alpha) \vartheta^{\frac{1}{1-\xi}}\left(q_{u}\right)^{-\frac{\xi}{1-\xi}}+2 \alpha q_{u}} s\left(d^{*}\right)=c,
$$

which is (22) in the main text where (30) and (50) imply

$$
s\left(d^{*}\right)=\frac{\Phi}{2} A^{\frac{1}{1-\beta}}(1-\Omega)\left[F(1+\Omega)-\gamma A d^{*}\right]
$$

and

$$
q_{u}=\frac{\delta E}{2 d^{*}(1-E)}
$$

given $L=1$.

\section{Parameter Values}

Table C1 reports the parameter values used in Section 2.5

\section{Table C1}

Parameters

\begin{tabular}{llc} 
Parameter & Description & Value \\
\hline$\alpha$ & Bargaining Weight & 0.5 \\
$\rho$ & Patience & 0.04 \\
$\delta$ & Per-period Seperation Shock & 0.05 \\
$\xi$ & Matching Function Elasticity & 0.5 \\
$\vartheta$ & Matching Function Constant & 0.4 \\
$\beta$ & Capital share in CB & 0.33 \\
$F$ & Max. Productivity & 20 \\
$\gamma$ & Mismatch Cost Parameter & 25 \\
$c$ & Vacancy Cost & 1
\end{tabular}




\section{Adding Vertical Specialization}

Throughout the main analysis we have assumed full symmetry within skills and within tasks. This assumption has allowed us to highlight the key mismatch mechanism at work in our model through the quantitative discussion of a closed-form equilibrium solution. In reality, however, such symmetry does not necessarily hold as skills and tasks are not only horizontally but also vertically differentiated. In other words, some skills are higher than others and some tasks are more productive than others. In this section we extend our model to check the robustness of our mechanism to asymmetry. While the extended model will not be amenable to closed-form solution, the numerical investigation of its equilibrium properties shows that our mechanism is still at work and may be even reinforced in the presence of vertical differentiation.

To facilitate comparison with the original model, the simplest way to introduce vertical differentiation is to keep the distributions of workers and thus firms uniform along the circle while changing the production possibilities. In particular, we make two new assumptions. First, larger $x$ and larger $y$ are associated with higher workers' skills and more productive firms' tasks respectively. Second, the mismatch between a firm with task $y$ and a worker with lower-than-ideal skill $x<y$ is more costly in terms of foregone productivity than an equally distant mismatch with larger-than-ideal skill $x>y$ by a factor $\tau \geq 1$ (with $\tau=1$ corresponding to the original symmetric case). In other words, for a given task and a given skill-task distance, employing an underskilled worker is more penalizing in terms of lost match surplus than hiring an overskilled one. This way the extended model also embeds a 'skill premium' in addition to the mismatch cost. ${ }^{39}$

The introduction of this asymmetry implies that the probability of forming a match now depends not only on the skill-task distance but also on the distribution of skills $x$ and tasks $y$ in the pools of unemployed workers and vacant firms respectively. Accordingly, the value $v_{u}(x)$ of being unemployed for a worker with skill $x$ now satisfies:

$$
\rho v_{u}(x)=q_{u}(\theta) \int_{\tilde{y} \in \Phi(y)} d_{v}(\tilde{y})\left(v_{e}(x, \tilde{y})-v_{u}(x)\right) d \tilde{y}
$$

\footnotetext{
${ }^{39}$ Changing the production possibilities as we do and changing the distribution of either side of the labor market are anyway equivalent. This is due to the fact that one can think of workers' skills and firms' tasks as ranks in their respective productivity distributions. Since workers' and firms' types as well as the production function are unobserved, it is not possible to separately identify each of them. See Hagedorn, Law and Manovskii (2017) and Kantenga and Law (2016) for a discussion of this point. Specifically, if the original distributions for skills and tasks are $H(x)$ and $G(y)$ respectively and the original production function is $\tilde{f}(\tilde{x}, \tilde{y})$, then we are simply performing the following transformation of the production function: $f(x, y)=f\left(F^{-1}(x), G^{-1}(y)\right.$. The simplest example is in the 1-dimensional case, where $x \sim[0,1]$ with $f(x)=3 x$ and $x \sim[0,3]$ with $f(x)=x$ are observationally identical.
} 
Analogously, the value of an unfilled vacancy $v_{v}(y)$ for a firm with task $y$ is given by:

$$
\rho v_{v}(y)=-c+q_{v}(\theta) \int_{\tilde{x} \in \Lambda(x)} d_{u}(\tilde{x})\left(v_{p}(\tilde{x}, y)-v_{v}(y)\right) d \tilde{x}
$$

Figures D1 and D2 report the equilibrium outcomes of the extended model for different degrees of asymmetry $\tau$ while holding the state of technology constant at $A=2.5$. These outcomes are obtained numerically through value function iteration on a grid of workers' skills $x$ and firms' tasks $y .{ }^{40}$ We then iterate over the surplus and matching density until they converge.

The three panels of Figure D1 depict the matching densities for different levels of $\tau=$ $(0.9,1,1.1)$ while fixing $A=3$ and $\tau=0.15$. Firms' tasks $y$ are displayed on the horizontal axis while workers' skills $x$ are displayed on the vertical axis. For all tasks and skills pairs, the panels show the simulated steady-state probabilities of being observed in a match. Blue areas are outside the matching sets of firms and workers so that the matching density of the corresponding pairs is zero. Color coding for the other areas goes from deep red to bright yellow in increasing order of matching density.

To interpret these color patterns recall that both tasks and skills are arranged along a circle $[0,1]$. For $\tau=1$ corresponds to the original model, in which all addresses on the circle are symmetric and their ordering from noon is inconsequential. The circle is turned into segments along the panel's axes and we can see that each task $y$ on the horizontal axis has a symmetric matching interval centered around the ideal skill $x=y$ along the vertical axis. Vice versa, each skill $x$ on the vertical axis has a symmetric matching interval centered around the ideal task $y=x$ along the horizontal axis. Moreover, all feasible matches have equal density as shown by the uniformly red areas.

The other two panels correspond to scenarios in which the mismatch cost is asymmetric. For $\tau=1.1$ mismatch at a given distance is more costly relative to the case of $\tau=1$ for underskilled workers (those with $x<y$ ), which is our case of interest. For comparison, in the reverse case with $\tau=0.9$ mismatch at given distance is more costly relative to the case of $\tau=1$ for overskilled workers (those with $x>y$ ). The density patterns in these two panels are perturbed by the fact that our distance metric $d(x, y)=\min [x-y+1, y-x]$ implies that very productive tasks at address $y$ just below 1 are very close along the circle to very low skills with address $x$ just above 0 , which creates a strong incentive to match despite

\footnotetext{
${ }^{40}$ Our numerical solution follows Hagedorn, Law and Manovskii (2017), who accommodate non-uniform distributions. They assume that the cost of posting vacancies adjusts so that the mass of vacancies equals the mass of unemployed workers. Differently from them we solve for the number of vacancies using equation:

$$
\rho V_{v}=-c+\frac{(1-\alpha) 2 q_{v}(\theta) \int_{y \in \Phi(y)} f(z) d z}{\delta+\rho+(1-\alpha) 2 q_{b}(\theta)+\alpha 2 q_{u}(\theta)} .
$$
}


Figure D1

Matching Set and Matching Density
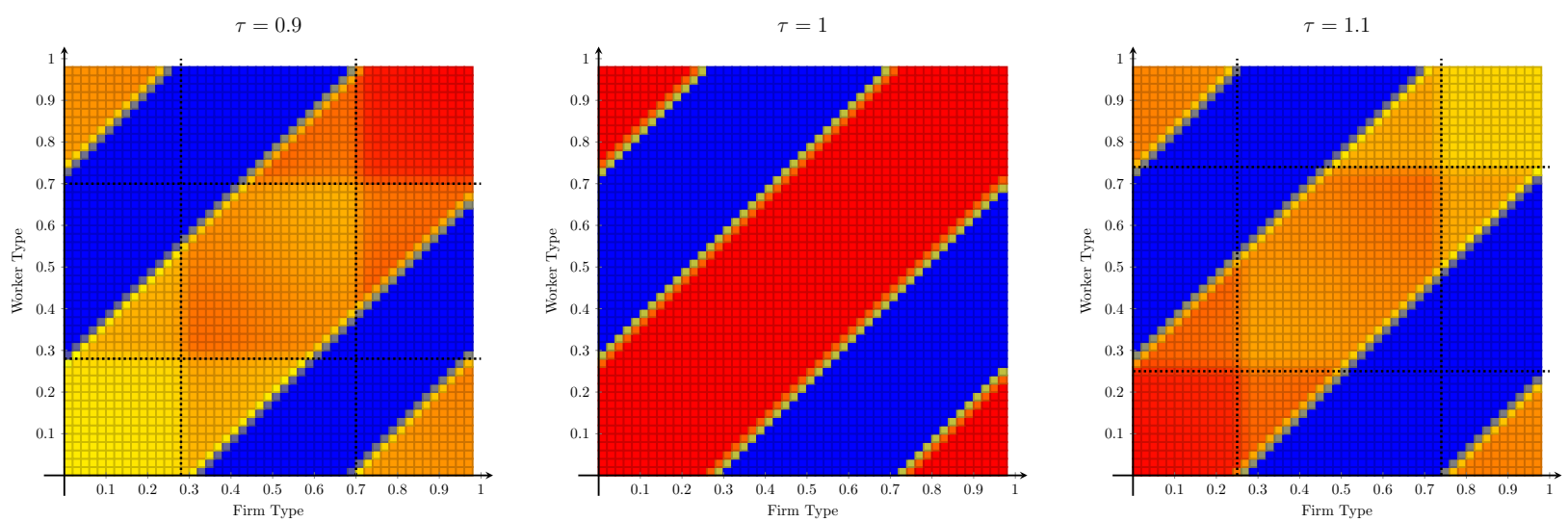

Figure D1 plots the matching densities for heterogeneous worker and firm types on the y and xaxis respectively for different degrees of vertical specialization $\tau$. Matching density increases from deep red to bright yellow. For $\tau=1$ vertical specialization is switched off and matching sets are independent of worker or firm types. For $\tau=1.1(\tau=0.9)$ overskilled (underskilled) matching is less costly and matching sets shrink for underskilled (overskilled) matches.

Figure D2

Employment and Selectivity with Vertical Specialization
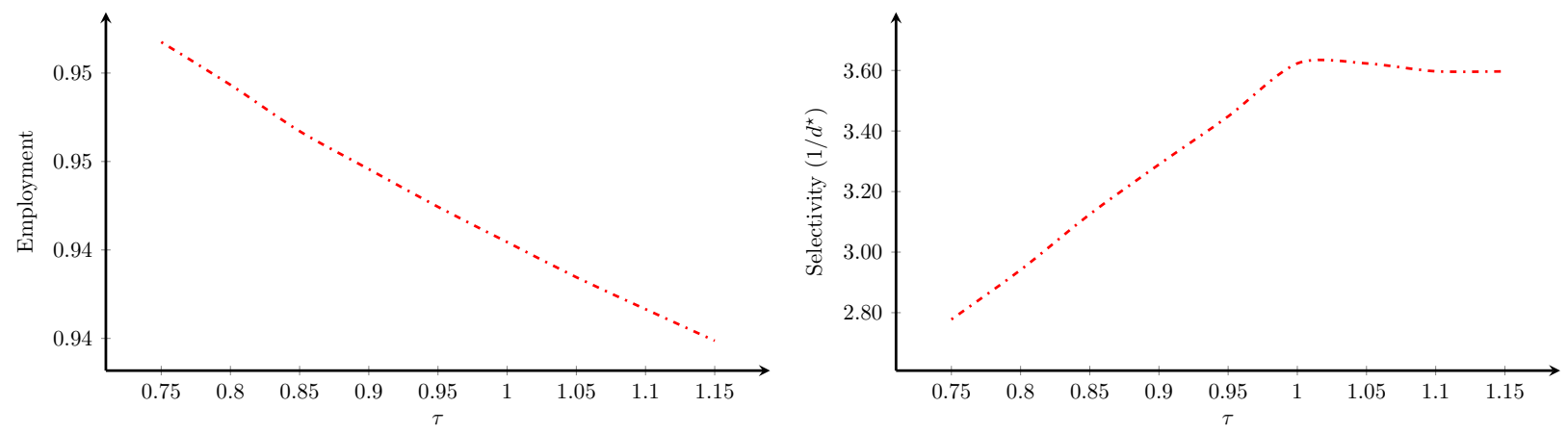

Figure D2 plots the employment levels and selectivity for different degrees of vertical specialization $\tau$ fixing $A=3$ and $\Omega=0.15$. As the vertical specialization increases, employment levels fall (left) as firms and workers become more selective. It confirms that the mismatch effect can dominate the productivity effect (if the state of technology is good enough) even in presence of vertical specialization. In the asymmetric case (higher $\tau$ ) the negative impact on employment is even stronger.

high matching cost per unit distance. Hence, to minimize the resulting distortions in the equilibrium density patterns, it is useful to focus on tasks and skills that are matched on the same round of the circle. This are the ones inside the inner dashed rectangles.

Comparing the panels we see that going from $\tau=1$ to $\tau=1.1$, the lower blue band becomes thicker whereas the upper blue band is unchanged. This means that the matching 
set shrinks from below as the most underskilled matches are not feasible anymore. In addition to this adjustment at the extensive margin, we also observe an adjustment at the intensive margin due to the relative change in density for pairs that are still matched in favor of those between high skills and high productivity tasks (those in brighter yellow). Analogously, we observe the opposite evolution going from $\tau=1$ to $\tau=0.9$ as in this case underskilled matching becomes less costly.

Figure D2 shows how the degree of vertical specialization $\tau$ on the horizontal axis affects employment and selectivity on the vertical axes. Throughout we fix the $A=3$ and $\Omega=0.15$. The figure shows that, when the state of technology is good enough, increasing vertical specialization (larger $\tau$ ) amplifies the dominance of the mismatch effect cover the productivity effect of technological change. In the asymmetric case of interest $(\tau>1)$, the negative impact on employment is even stronger relative to the case of no vertical specialization $(\tau>1)$ discussed in the main text.

What we refer to as the additional vertical specialization channel is nothing but a general catch word encompassing all types of mechanisms like skill-biased as well as routine-biased technological change that imply some type of skewness in the distribution of workers' productivity. While work on skill-biased TC like Griliches (1969); Krusell et al. (2000) or Acemoglu and Zilibotti (2001) stress skill-complementarities in the context of wage inequality, our focus lies on explaining an observed fall in employment. Related Acemoglu and Restrepo (2018b) argue that under routine-biased technological change for certain degrees of substitution between capital-labor a negative effect on employment can arise, while in our setting with horizontal mismatch in the background the negative employment effect under vertical specialization arises naturally as long as the mismatch effect dominates the productivity effect.

Overall, the economic mechanism highlighted in the original symmetric model is confirmed, and the associated results are even amplified for employment in the extended asymmetric model as an additional vertical specialization effect reinforces the original horizontal specialization one. This is the way SBTC and CBTC interact in our framework. 
CENTRE FOR ECONOMIC PERFORMANCE

Recent Discussion Papers

\begin{tabular}{|c|c|c|}
\hline 1694 & Ulrich J. Eberle & Damned by Dams? Infrastructure and Conflict \\
\hline 1693 & $\begin{array}{l}\text { Abel Brodeur } \\
\text { Andrew E. Clark } \\
\text { Sarah Flèche } \\
\text { Nattavudh Powdthavee }\end{array}$ & $\begin{array}{l}\text { COVID-19, Lockdowns and Well-Being: } \\
\text { Evidence from Google Trends }\end{array}$ \\
\hline 1692 & $\begin{array}{l}\text { Fabrice Defever } \\
\text { José-Daniel Reyes } \\
\text { Alejandro Riaño } \\
\text { Gonzalo Varela }\end{array}$ & $\begin{array}{l}\text { All These Worlds are Yours, Except India: } \\
\text { The Effectiveness of Cash Subsidies to Export } \\
\text { in Nepal }\end{array}$ \\
\hline 1691 & $\begin{array}{l}\text { Adam Altmejd } \\
\text { Andrés Barrios-Fernández } \\
\text { Marin Drlje } \\
\text { Joshua Goodman } \\
\text { Michael Hurwitz } \\
\text { Dejan Kovac } \\
\text { Christine Mulhern } \\
\text { Christopher Neilson } \\
\text { Jonathan Smith }\end{array}$ & $\begin{array}{l}\text { O Brother, Where Start Thou? Sibling } \\
\text { Spillovers on College and Major Choice in } \\
\text { Four Countries }\end{array}$ \\
\hline 1690 & $\begin{array}{l}\text { Michael Amior } \\
\text { Alan Manning }\end{array}$ & $\begin{array}{l}\text { Monopsony and the Wage Effects of } \\
\text { Migration }\end{array}$ \\
\hline 1689 & Frank Pisch & $\begin{array}{l}\text { Managing Global Production: Theory and } \\
\text { Evidence from Just-in-Time Supply Chains }\end{array}$ \\
\hline 1688 & $\begin{array}{l}\text { Barbara Petrongolo } \\
\text { Maddalena Ronchi }\end{array}$ & $\begin{array}{l}\text { A Survey of Gender Gaps through the Lens of } \\
\text { the Industry Structure and Local Labor } \\
\text { Markets }\end{array}$ \\
\hline 1687 & $\begin{array}{l}\text { Nick Jacob } \\
\text { Giordano Mion }\end{array}$ & On the Productivity Advantage of Cities \\
\hline 1686 & $\begin{array}{l}\text { Andrew E. Clark } \\
\text { Anthony Lepinteur }\end{array}$ & $\begin{array}{l}\text { A Natural Experiment on Job Insecurity and } \\
\text { Fertility in France }\end{array}$ \\
\hline
\end{tabular}




\begin{tabular}{|c|c|c|}
\hline 1685 & $\begin{array}{l}\text { Richard Disney } \\
\text { John Gathergood } \\
\text { Stephen Machin } \\
\text { Matteo Sandi }\end{array}$ & $\begin{array}{l}\text { Does Homeownership Reduce Crime? A } \\
\text { Radical Housing Reform in Britain }\end{array}$ \\
\hline 1684 & $\begin{array}{l}\text { Philippe Aghion } \\
\text { Roland Bénabou } \\
\text { Ralf Martin } \\
\text { Alexandra Roulet }\end{array}$ & $\begin{array}{l}\text { Environmental Preferences and Technological } \\
\text { Choices: Is Market Competition Clean or } \\
\text { Dirty? }\end{array}$ \\
\hline 1683 & Georg Graetz & Labor Demand in the Past, Present and Future \\
\hline 1682 & $\begin{array}{l}\text { Rita Cappariello } \\
\text { Sebastian Franco-Bedoya } \\
\text { Vanessa Gunnella } \\
\text { Gianmarco Ottaviano }\end{array}$ & $\begin{array}{l}\text { Rising Protectionism and Global Value } \\
\text { Chains: Quantifying the General Equilibrium } \\
\text { Effects }\end{array}$ \\
\hline 1681 & $\begin{array}{l}\text { Felipe Carozzi } \\
\text { Christian Hilber } \\
\text { Xiaolun Yu }\end{array}$ & $\begin{array}{l}\text { On the Economic Impacts of Mortgage Credit } \\
\text { Expansion Policies: Evidence from Help to } \\
\text { Buy }\end{array}$ \\
\hline 1680 & $\begin{array}{l}\text { Paul Frijters } \\
\text { Christian Krekel } \\
\text { Aydogan Ulker }\end{array}$ & $\begin{array}{l}\text { Machiavelli Versus Concave Utility } \\
\text { Functions: Should Bads Be Spread Out Or } \\
\text { Concentrated? }\end{array}$ \\
\hline 1679 & $\begin{array}{l}\text { Antoine Dechezleprêtre } \\
\text { David Hémous } \\
\text { Morten Olsen } \\
\text { Carlo Zanella }\end{array}$ & $\begin{array}{l}\text { Automating Labor: Evidence from Firm-Level } \\
\text { Patent Data }\end{array}$ \\
\hline 1678 & Michael Amiior & $\begin{array}{l}\text { The Contribution of Immigration to Local } \\
\text { Labor Market Adjustment }\end{array}$ \\
\hline 1677 & $\begin{array}{l}\text { Swati Dhingra } \\
\text { Silvana Tenreyro }\end{array}$ & $\begin{array}{l}\text { The Rise of Agribusiness and the } \\
\text { Distributional Consequences of Policies on } \\
\text { Intermediated Trade }\end{array}$ \\
\hline
\end{tabular}

The Centre for Economic Performance Publications Unit

Tel: +44 (0)20 79557673 Email info@ cep.lse.ac.uk

Website: http://cep.lse.ac.uk Twitter: @CEP_LSE 